\title{
On the evolution of conscious attention
}

\author{
Harry Haroutioun Haladjian \\ School of Social Sciences and Psychology, University of Western Sydney (Bankstown) \\ Locked Bag 1797, Penrith, NSW 2751 Australia
}

Carlos Montemayor

Department of Philosophy, San Francisco State University

San Francisco, CA 94132 USA

\begin{abstract}
This paper aims to clarify the relationship between consciousness and attention through theoretical considerations about evolution. Specifically, we will argue that the empirical findings on attention and the basic considerations concerning the evolution of the different forms of attention demonstrate that consciousness and attention must be dissociated regardless of which definition of these terms one uses. To the best of our knowledge, no extant view on the relationship between consciousness and attention has this advantage. Because of this characteristic, this paper presents a principled and neutral way to settle debates concerning the relationship between consciousness and attention, without falling into disputes about the meaning of these terms. A decisive conclusion of this approach is that extreme views on the relationship between consciousness and attention must be rejected, including identity and full dissociation views. There is an overlap between the two within conscious attention, but developing a full understanding of this mechanism requires further empirical investigations.
\end{abstract}

Keywords: consciousness, attention, conscious attention, evolution

\section{On the evolution of conscious attention}

Herbert Spencer famously wrote that "If the doctrine of Evolution is true, the inevitable implication is that Mind can be understood only by observing how Mind is evolved" (Spencer, 1855 , p. 291). Given the general importance of the theory of evolution in scientific explanations of biology, this statement seems unchallengeable. The last few decades of research in psychology and neuroscience, however, show that it is an ambiguous assertion. The conscious mind has proved to be elusive when it comes to evolutionary explanations, to the extent that many theorists argue that phenomenal consciousness ${ }^{1}$ cannot be adaptive because it has no specific function (e.g., Chalmers, 1996). Although the consensus is that Spencer's claim must hold for most cognitive processes, phenomenal conscious experience seems to escape functional explanations and has consequences that have not been properly understood. This paper focuses on one of these

\footnotetext{
${ }^{1}$ Phenomenal consciousness is the subjective experience of "what it is like" to be in a certain mental state, as Nagel (1974) famously described.
}

Note: This is a near final draft; the final publication is available at Springer via http://dx.doi.org/10.3758/s13423-014-0718-y Please cite: Haladjian, H. H., \& Montemayor, C. (in press). On the evolution of conscious attention. Psychonomic Bulletin \& Review. 
consequences: the tenuous account of the apparent relationship between consciousness and attention.

While most cognitive psychologists agree that attention - the selective filtering of perceptual information - must have been an early adaptation in the evolution of cognitive systems (Ward, 2013), none would consider consciousness to be an early adaptation, but rather a later adaptation in cognitive development. In this sense, which has yet to be fully clarified, consciousness may help serve the purpose of controlling integrative aspects of selective attention (e.g., see Rensink, 2014). Nevertheless, a longstanding claim in the literature is that evolutionary considerations are useless for an understanding of consciousness because conscious awareness seems to lack any specific function, since integrative processes can occur without conscious awareness (e.g., Mudrik, Faivre, \& Koch, in press; Talsma, Senkowski, Soto-Faraco, \& Woldorff, 2010; Zmigrod \& Hommel, 2011). Some even claim that consciousness might be a spandrel, that is, a by-product resulting from increasing complexity in brain structures that does not serve an evolutionarily adaptive purpose (e.g., see Carruthers, 2000; Dennett, 2005; Gould \& Lewontin, 1979; Polger \& Flanagan, 2002; Rosenthal, 2008). This creates a fundamental problem in our current understanding of consciousness because it seems to prevent a functional analysis of conscious attention, that is, the "reportable" type of attention that is part of conscious awareness (i.e., where the contents of attention are consciously accessible such that one could report detecting this information). This specific problem has not received a sustained treatment in the literature and has decisive consequences concerning the relationship between consciousness and attention.

Since most theorists argue for the nonadaptability of phenomenal consciousness, an important theoretical implication is the inherent dissociation between consciousness and attention. That is, the relationship between attention and consciousness cannot be one that co-evolved in a way that links the two functionally under this perspective. Surprisingly, little focus has been given to the evolution of attention (but see Cosmides \& Tooby, 2013; Tooby \& Cosmides, 1995; Ward, 2013; Wright \& Ward, 2008, pp. 235-241), especially in terms of how it relates to the evolution of consciousness, which has received more treatment in the literature (e.g., Edelman, Baars, \& Seth, 2005; Feinberg \& Mallatt, 2013; Nichols \& Grantham, 2000; Polger \& Flanagan, 2002; Seth \& Baars, 2005).

Evolution, therefore, becomes a central consideration against theories that identify consciousness with attention. For example, Prinz (2012) argues that consciousness should be identified with attention, since otherwise one might have to provide an account of consciousness that would be theoretically difficult to defend (e.g., by calling on dualism); thus, he rejects proposals for different kinds of consciousness and argues that there is only phenomenal consciousness. By "attention", however, Prinz means something like "attention to information that is available for working memory", which denies that some forms of consciousness even should be called "consciousness" under this proposal. This means that consciousness just is, for Prinz, information that is available for working

Note: This is a near final draft; the final publication is available at Springer via http://dx.doi.org/10.3758/s13423-014-0718-y Please cite: Haladjian, H. H., \& Montemayor, C. (in press). On the evolution of conscious attention. Psychonomic Bulletin \& Review. 
memory, plus a subjective phenomenal experience (Prinz, 2012, pp. 5-6). By contrast, Tallon-Baudry (2012) argues that the findings allegedly confirming such identity views are based on confused and biased approaches to data analysis. More importantly, she found neurological evidence suggesting a significant dissociation between the neural correlates of attention-access to information and conscious experience.

Although the amount of experimental evidence against the identity view keeps growing (e.g., Dehaene \& Naccache, 2001; Lamme, 2006; Tallon-Baudry, 2012; van Boxtel, Tsuchiya, \& Koch, 2010), an evolutionary approach provides a principled theoretic way to explain why scientists are finding such dissociations. Thus, instead of arguing for dissociation based on inductive arguments from specific bodies of evidence, we argue for a more decisive and principled reason for dissociation based on the importance of evolution in scientific explanations. The unique advantage of this theoretical approach is that it is interpretation-independent-regardless of how the varieties of "consciousness" or "attention" are defined within the theories currently available, there will be a substantial dissociation between them. This eliminates problems concerning the multiple definitions of these terms and puts the current evidence under a clearer theoretical light.

This new approach to the debate concerning the relationship between consciousness and attention is decisive in at least two respects. If it is true that consciousness has no cognitive function, then the type of dissociation between consciousness and attention must be either the most severe (full dissociation) or very severe, with very few cases of conscious attention. Alternatively, if consciousness has a specific evolutionary function and theorists seek to provide an identity view or even a mild dissociation view, then they will face the challenge of specifying how consciousness, as a cognitive function, coevolved with attention, which can be defined in terms of specific types of attentive functions (e.g., voluntary, objectbased, feature-based, spatial). We suspect that this latter possibility will not materialize given our current theoretical understanding. Another complication for identifying consciousness with attention is that different forms of attention must have evolved at different times, further dissociating them from conscious attention.

\section{Attention as an early adaptation}

In their influential paper on the evolution of cognitive functions, Tooby and Cosmides (1995, p. 1195) argue that attention must be one of the earliest adaptations in the evolution of the human mind. Although they talk about perception more generally in the same passage, it is clear that they refer to basic low-level attentional processes, such as those involved in navigation and feature detection. Indeed, one can hardly think of a more basic cognitive function than selective attention for motor control and navigation. For example, many animals navigate by exploiting features of the environment, such as locating the position and angle of the sun to determine orientation, or performing computations on how locations of external features relate to their egocentric frame of reference. Beyond this, there has been minimal examination of the evolution of 
attention, with only brief discussions found in the current literature (e.g., Cosmides \& Tooby, 2013; Ward, 2013; Wright \& Ward, 2008, pp. 235-241).

Spatial and feature-based attention are fundamental for performing tasks critical for survival. Parsing the environment into objects and spatial coordinates, or predator/prey and conspecific, requires these forms of attention. These basic forms of attention can interact with other cognitive capacities, such as short-term and long-term memory, in order to produce richer representations. Animals with robust nervous systems can use episodic and semantic memory to recognize targets in their environment and increase the repertoire of objects and features that can be attended at any specific time. These capacities, in turn, become the basis for optimal decision-making, action planning, and task-switching. These are behaviors that animals display in their environment and which require a fair amount of cognitive integration. It is likely that skills related to attention were critical for survival as competition for resources increased during the Cambrian era. Incidentally, some researchers, particularly in the biological sciences, argue that the increase in information complexity that accompanied integrative processes of attention and memory is an indicator of the emergence of consciousness (e.g., Nichols \& Grantham, 2000). The problem with this proposal is that most functions of feature integration and the higher complexity purportedly related to conscious experience can be fully understood and explained by attention without phenomenal awareness (e.g., Mudrik, et al., in press).

The evolutionary drives of competition and the struggle for survival require that species develop some form of interfacing agent-based "attention", with attentional mechanisms that were selected because of their automaticity as immediate responses to the environment.

Reflexive reactions to features of the environment that immediately trigger or grab attention must be, therefore, interfaced with processes of associative learning that initiate with sustained voluntary attention and eventually became automatic or effortless. Success in search tasks and behavioral routines, such as those associated with hunting, becomes a staple of the fitness of a species. The degree of cognitive integration required for this interaction between the different forms of attention is significant and marks an important transition in the way in which information is stored - a transition in informational complexity, as defined by Smith and Szathmáry (1995). Furthermore, the integration required for search behavior also demands short-term and long-term memory, as well as mappings between frames of reference that constitute the egocentric perspective present in creatures with a central nervous system (see Merker, 2005).

Thus, many forms of attention must be adaptive and must have evolved very early, as organisms diversified and developed central nervous systems in order to cope with ever more complex and demanding interactions with their ecosystems. From basic discrimination to highly integrated search behavior, there is a repertoire of attentive skills that must be in place in order for a species to adapt and survive. Crucially, these skills do not constitute a ladder from lower forms of cognitive systems to higher forms, and higher forms of cognitive complexity are not causally necessitated by lower forms. Rather, the transition to complex forms of attention is

Note: This is a near final draft; the final publication is available at Springer via http://dx.doi.org/10.3758/s13423-014-0718-y Please cite: Haladjian, H. H., \& Montemayor, C. (in press). On the evolution of conscious attention. Psychonomic Bulletin \& Review. 
best captured in terms of intentionality (i.e., the "aboutness" of cognitive states that makes them directed toward a specific thing) and of feature binding into higher-level object representations. Creatures with the capacity to integrate representations with content (about the environment, its objects, and spatiotemporal structure) are capable of many other abilities that depend on attention and representation, such as learning and remembering information. Similarly, communication and language capacities are related to this form of high-level symbolic representation.

One can illustrate the previous point by examining the evolution of sensory modalities. Animals with a nervous system capable of registering light waves and encoding that information in a representational fashion, which entails intentionality, can cope with many tasks that depend on attending to features of the environment. In this sense, intentionality must be present at some level for goal-directed behavior. For example, one can imagine a creature that is capable of selective attention for object and feature recognition within a sensory modality equivalent to human vision. Such a visual sensorial apparatus would not be inferior to the more complex cross-modal sensorial registration that characterizes mammals, for instance. This cross-modal integration allows animals to significantly enhance the degree of confirmation of information across different encoding systems (e.g., light or sound waves), and interactions between different modalities can facilitate perception, for example, by enhancing motion perception through the localization of sounds associated with an object (Zmigrod, Spapé, \& Hommel, 2009).
Perceptual questions that the brain needs to answer within a single modality (e.g., is this the same object that was moving a second ago?) can be formulated within a broader network of possibilities, such as the simultaneous instantiation of properties detected crossmodally from a single distal stimulus. Not only spatial attention, but temporally-sustained attention becomes more flexible and dynamic. It is well known that each modality has a unique simultaneity window and that these windows differ considerably (see Pöppel, 1988). These different windows play a compensatory role for the speeds of the energies that they are designed to register, and are part of a cross-modal window of simultaneity required for motor control tasks (Montemayor, 2013). The evolution of different modalities, therefore, allowed for a flexible, dynamic, highly integrative, and evidence-driven centralized system for information processing.

Such arguments indicate that one cannot reasonably deny that attention, in its many forms, is an adaptation. The key point, however, is that these forms of attention are defined functionally, and there are strong arguments against functional accounts of phenomenal consciousness. While the cognitive functions associated with attention are fundamental adaptations in the course of the evolution of the central nervous system, none of these functions seem to require conscious awareness, which is a point on which many researchers agree (e.g., Dehaene \& Naccache, 2001; Lamme, 2006; van Boxtel, et al., 2010).

Therefore, although selective attention is certainly an early adaptation in the evolution of the human brain, the claim that conscious attention is an adaptation is considerably more

Note: This is a near final draft; the final publication is available at Springer via http://dx.doi.org/10.3758/s13423-014-0718-y Please cite: Haladjian, H. H., \& Montemayor, C. (in press). On the evolution of conscious attention. Psychonomic Bulletin \& Review. 
controversial. The functional-computational approach that is assumed in evolutionary theory and cognitive psychology has been criticized as useless to account for consciousness by many theorists (e.g., Block, 1995; Chalmers, 1996). Even if one defines consciousness functionally - as in global workspace accounts (Baars, 1988, 1998; Dehaene \& Naccache, 2001), or an integrative account (Tononi, 2008, 2012), or even in an account that emphasizes learning (Meuwese, Post, Scholte, \& Lamme, 2013) - one can still argue that attention is an early adaptation and that the alleged functions of consciousness must be a much later addition to the repertoire of cognitive capacities, thus demonstrating their dissociation based on this early versus late adaptation argument. Furthermore, there seems to be consensus concerning the claim that consciousness appeared recently in the evolution of cognitive capacities. While there are several accounts on the evolution of consciousness (ranging from complete skepticism to proposals that consciousness may be a spandrel), none of these accounts claim that consciousness is an adaptation. Cognitive scientists are, therefore, confronted with the puzzling challenge of reconciling conflicting claims concerning consciousness and attention into a theoretically unified account of the evolution of conscious attention.

In what follows, we explore the theoretical options that are available and present a theory for the evolution of conscious attention that entails a severe dissociation between consciousness and attention. While most forms of attention must have evolved early as adaptations, no form of conscious awareness was required as an early adaptation, suggesting that the overlap between consciousness and attention - conscious attention - is an equally recent phenomenon and must be the exception, rather than the rule, with respect to how consciousness interacts with attention. ${ }^{2}$

\section{Attention, functionalism, and evolution}

The voluminous experimental research on different forms of visual attention demonstrates that attention needs to be defined functionally. In fact, definitions of the forms of attention aim at capturing different functions (Rensink, 2014). For example, the most basic form of selective attention has the broad function of filtering information and optimally distributing cognitive resources to modulate information processing. The idea that attention performs a kind of filtering function is central, and early theories of attention defined it in terms of monitoring and filtering.

There are different types of information, however, that can be selected by attentional mechanisms. (We will limit our discussion to the visual domain, though it is relevant to the other sense modalities.) For example, featurebased attention selects various types of perceptual features in a visual scene, such as color, line segment orientation, and motion signals. Spatial attention has the function of quickly parsing the surrounding environment into regions for information registration. Objectbased attention is a mid-level form of attention that specifically targets units of discrete objects, and the mechanisms for detecting, tracking, and

\footnotetext{
${ }^{2}$ The various levels of the consciousness and attention dissociation (CAD) are examined in detail in Montemayor \& Haladjian (in press).
} 
counting objects have been found in many species. Using Spelke's (1994) terminology, these forms of attention are constitutive of an ancient and fundamental core knowledge that structures many types of cognition and information processing. While all forms of attention are defined in terms of functions related to information processing, some forms of attention are more basic than others. Based on the current theoretical and empirical understanding of attention, it is plausible to hypothesize that different forms of attention evolved at different times. This thesis has critical consequences for the evolution of conscious attention and for understanding the relationship between consciousness and attention.

\subsection{Selective attention as the earliest form of attention}

Once one identifies the functions of attention, the neural correlates of these functions can be studied across species. For example, selective attention and object-based attention, which include basic discrimination functions, involve substantial portions of the cortex in humans. Even simple shifts of attention between objects activates "a large network of cortical areas" (Ward, 2013, p. 54). Shifting focus from one object to another is a fundamental function of attention, indispensible for selectively interpreting spatial information and without which basic navigational or visual search tasks would be impossible. Brain imaging studies on humans and non-human primates also identify a hierarchical organization of visual areas that increase in processing complexity (for a review, see Kastner \& Ungerleider, 2000). This hierarchical organization mirrors the increasingly complex functions of vision that correspond to the different forms of visual attention required to select and integrate information within this organization.

From an evolutionary perspective, the ability to attend to multiple aspects of the environment is so ubiquitous that it must be physically instantiated by different neural structures across species. Forms of selective attention to environmental features have been found in many species, including those with minuscule brains, such as fruit flies and dragonflies (Wiederman \& O'Carroll, 2013). While it is clear that insects do not enjoy the attention capacities of humans and animals with larger brains, this is an extremely relevant fact because fruit flies diverged 500 million years ago from the human branch in the evolution of different types of nervous systems (Ward, 2013). This form of selective attention must be causallydriven in the sense that it depends on automatic processes that detect features according to principles of salience, and is selective in the sense that such features trigger a relevant goalrelated behavior (resulting from adaptive influences) or become available for selection by the filtering mechanisms of attention.

The multiple correlates of the functions of basic selective and object-based attention presents intriguing possibilities. For example, the cortex is a large area of the brain and costly in terms of energy expenditure. Therefore, basic forms of selective attention must be physically instantiated in much smaller and less costly brain areas (as Ward suggests). This indicates that forms of selective attention have evolved at different times in different species with very diverse neural anatomies. In fact, the presence of such a variety of neural systems that support attention suggests that selective attention has 
evolved repeatedly and independently in different species, as is generally believed to be the case in the evolution of various brain systems (Striedter, 2006).

We must emphasize that we are not claiming that these forms of cross-species attention are identical in all respects. It seems obvious that one reason why attention activates vast areas of the human cortex is because of the rich and highly integrated contents that human attention is capable of encoding. We do not argue, for example, that any form of signal detection counts as selective attention. Rather, we are simply pointing to the empirically-confirmed fact that many species with small nervous systems are capable of shifting attention from one object to another, as insect navigational capabilities demonstrate (see Gallistel, 1990a, for discussions about navigational functions that depend on such capabilities, like the solar ephemeris function). These cognitive functions are verifiable empirically and are only possible because of the integration of information that is being represented and attended to, rather than the mere causal interaction between internal biology and external factors. This kind of attention, manifested in simple shifts, must be among the earliest cognitive functions (but we shall remain neutral with respect to the demarcating question of which species have attention capacities similar to human attention).

The likelihood that selective attention evolved repeatedly and independently across many species suggests that it is a crucial and very basic adaptation (Ward, 2013). Following Smith and Szathmáry's (1995) proposal concerning the evolutionary importance of transitions in how information is stored and used, the appearance of cognitive systems capable of discriminating and selectively attending to different features certainly must have marked a new transition into more integrated and complex behaviors. At a minimum, selective attention reveals purposeful behavior and a minimal form of directed intentionality. As more complex forms of object recognition became available, for example by basing attention on conceptual content retrieved from long-term memory, better planning became available. Yet, the resources of selective attention still would be based on the same early adaptations that animals needed for performing basic survival activities, such as navigating through their environment.

Parenthetically, it is productive to contrast the predominance of attention as an early adaptation with the rarity of what some have suggested to be the basic functions that underlie conscious awareness: the capacities for language and mindreading (see Carruthers, 2000; Dennett, 1969, 2005). Language, according to some theorists (e.g., Fitch, Hauser, \& Chomsky, 2005), may itself be a spandrel and a uniquely human capacity. Mindreading (or having a theory of mind) seems to be more widespread, but robust forms of mindreading also seem to be uniquely human, such as those required to pass the false-belief task or having socially specified forms of attention to detect the intentions of others (Tomasello, 1999). Notice that these are the views that do not consider consciousness to be an illusion, a mystery, or a primitive feature of the universe.

Even if one thinks that cognitive function could explain the emergence of consciousness, attention and consciousness would still be dissociated since the lower-level forms of attention have evolved in organisms that do not

Note: This is a near final draft; the final publication is available at Springer via http://dx.doi.org/10.3758/s13423-014-0718-y Please cite: Haladjian, H. H., \& Montemayor, C. (in press). On the evolution of conscious attention. Psychonomic Bulletin \& Review. 
seem to have conscious awareness (see Griffin $\&$ Speck, 2004). This is not to deny that there may be phenomenal consciousness in animalssome animals with central nervous systems may experience pain or color in ways that resemble human experiences. Yet, the functions of attention would precede or at least be evolutionarily independent from these neural processes (see Tallon-Baudry, 2012, for a discussion on the possible evolutionary differences between consciousness and attention based on their underlying neural structures). Before examining the possibility of an evolutionarily advanced conscious attention, we should describe the empirically-accepted forms of attention and how they relate to mechanisms for cross-modal integration.

\subsubsection{Forms of selective attention: feature- based attention}

Feature-based attention is a more primitive information selection mechanism that interacts with low-level perceptual processes. These information processing systems are organized according to specialized brain regions responsible for registering specific types of visual information, such as color, motion, or segment orientation (for a review, see Maunsell $\&$ Treue, 2006). This organization is related to the modularity of mind hypothesis (Fodor, 1983), such that different perceptual modules developed for processing different features although they are not clearly independent regions in the brain and may be better described as organized into distributed networks (see Finlay \& Brodsky, 2006). Feature-based attention interacts with these low-level systems to select information in a typically automatic manner, but this selection process can be biased by higher-level signals based on task demands.
In support of a functionally modular organization of feature-based attention, neural studies have identified a hierarchically organized visual cortex, with basic feature processing occurring in lower areas of the brain (see Hubel, 1995, pp. 93-125; Koch, 2004, pp. 49-86). Visual information from the retina flows through the optic nerve into the lateral geniculate nucleus (LGN) of the thalamus before reaching the primary visual cortex (V1). From there, information flows via two major pathways, the dorsal and the ventral, also referred to as the "where" and the "what" pathways respectively (Kastner \& Ungerleider, 2000; Ungerleider \& Haxby, 1994). The dorsal "where" pathway tends to process information about motion and location of objects, with the middle temporal (MT) area being especially sensitive to motion and higher contrast stimuli (Tootell et al., 1995). The ventral "what" pathway processes featural information about objects including color, shape, or orientation. For example, color information, which is initially detected by retinal cones, is processed in the LGN and areas V1 and V2 (for a review, see Gegenfurtner, 2003). Orientation-specific cells in V1 detect orientation, contour, and curvature, which are important for determining shapes and object-hood (Hubel \& Wiesel, 1962).

Another characterization of these two processing streams proposes that the dorsal stream supports "vision for action" while the ventral stream supports "vision for perception" (Milner \& Goodale, 1995, 2008). On this account, the dorsal pathway provides visual information for action-planning and the execution of motor commands and is processed separately from the ventral pathway, which 
provides the contents of visual experience. Often, the visual information for successful actions only travels in the dorsal pathway and serves its purpose without reaching awareness. The importance of noting these separate processing streams is that some observed dissociations between attentional processes and consciousness depend on this anatomical organization, where information from the dorsal processing stream does not need to reach conscious awareness in order to affect behavior.

Further up in the visual cortex, area V4 processes orientation information as object shapes. The global grouping of contour information (i.e., the Gestalt notion of "good continuation") is crucial for the formulation of shapes and objects (Geisler, Perry, Super, \& Gallogly, 2001; Kovács, 1996) and relies on cortical processes that are responsible for global contour integration processes (Tanskanen, Saarinen, Parkkonen, \& Hari, 2008). This integration process also explains how the visual system can extract shape information from images based on low-level processing mechanisms (Marr, 1980).

Feature-based attention, therefore, can be considered a fundamental and basic form of attention from which richer representations are built. Evidence among both invertebrates and vertebrates exists for this type of basic-level attention, from insects to primates (Ward, 2013). Generally, this is a "bottom-up" attention that operates within feature-rich environments based on its role in the evolutionary development of these systems (Rensink, 2014). It is also hierarchically organized, such that different levels in the visual cortex are responsible for certain features, and a biasing of the competition for feature selection can occur on several of these levels through feedback loops that integrate the influence of higher-level attentional processes. The results of these independent feature-specific selection mechanisms, which then may be organized into feature maps, can be linked together based on spatiotemporal information to form more detailed representations (see Treisman \& Gelade, 1980; Treisman \& Zhang, 2006).

\subsubsection{Forms of selective attention: spatial} attention

Spatial attention filters information based on spatial coordinates and is another important mechanism that evolved early in order to aid navigation and other goal-directed motor behaviors. An influential model for this form of attention is the "spotlight model" (Posner, Snyder, \& Davidson, 1980), where attention can be focused on a specific region and shifted around as needed. Spatial attention can be diffuse and spread over the entire visual field but without much fidelity in regards to the information that is processed, or it can be focused on a particular area with higher resolution. This range of attentional resolution has been described as a "zoom lens" that distributes resources in a top-down manner as needed (Eriksen \& Yeh, 1985). Therefore, spatial attention is thought to be able to operate on discrete objects, empty space, or spread globally to quickly determine the gist of the information present across the visual field. Indeed, recent studies show that a distributed attention can capture quickly a statistical summary representation of the information outside of the focus of attention (e.g., Alvarez \& Oliva, 2008). Such studies support the idea that visual information can be pooled into an ensemble summary representation to help

Note: This is a near final draft; the final publication is available at Springer via http://dx.doi.org/10.3758/s13423-014-0718-y Please cite: Haladjian, H. H., \& Montemayor, C. (in press). On the evolution of conscious attention. Psychonomic Bulletin \& Review. 
overcome the visual processing limits imposed by attention-demanding tasks, indicating a more basic and independent form of spatial attention.

The neural systems that support spatial attention are thought to be located in the precentral sulcus, intraparietal sulcus, and lateral occipital sulcus, areas related to motor activity (Beauchamp, Petit, Ellmore, Ingeholm, \& Haxby, 2001). Although some studies have identified activations as early as V1, spatial attention tends to be modulated in higher cortical stages, such as the ventral occipitotemporal cortex (Brefczynski \& DeYoe, 1999), and the act of shifting attention from one spatial location to another is induced by signals from the posterior parietal cortex (Yantis et al., 2002). Attentional capture (typically considered to be a more automatic deployment of attention) occurs in the superior parietal cortex, which also is related to spatial shifts of attention (de Fockert, Rees, Frith, \& Lavie, 2004). The significance of such findings is that they differentiate the systems that shift spatial attention from those that maintain sustained attention. Although classifications of neural systems supporting different aspects of spatial attention are still under scrutiny, there is a sense of how different processes are localized in different brain regions, which differentiates these forms of attention based on their functions. More complex spatial abilities are present in vertebrates and seem concentrated in the right brain hemisphere, with the frontal and parietal structures being particularly active during spatial attention tasks and have some overlap with working memory networks (Awh \& Jonides, 2001). More specialized shifts of attention, such as covert attention, appear to require neurons that are involved in executive control and only found in higher primates such as apes and humans (Wright \& Ward, 2008, p. 240).

Covert attention is a particularly insightful form of spatial attention, which refers to the willful shift of attention outside the center of one's gaze without changing the direction of gaze (Carrasco, 2011; Posner, 1980; Posner, Cohen, \& Rafal, 1982; Wright \& Ward, 2008). That is, the focus of attention can be oriented independently of the physical manipulation of gaze - in contrast to overt attention, which refers to what is at the center of attention and on the fovea (center) of the eye. Covert attention has been shown through various tasks where observers view a center of a stimulus display but shift their focus of attention to a target in the periphery without moving their eyes or making other physical movements (e.g., Peterson, Kramer, \& Irwin, 2004). This form of attention is particularly important for the planning of saccadic eye movements, for example, by covertly detecting where the eye needs to shift its gaze in order to obtain more detailed information from that region (Yeshurun \& Carrasco, 1998). This attentional shift is faster than making eye movements and tends to favor shifting toward objects (Horowitz, Holcombe, Wolfe, Arsenio, \& DiMase, 2004). The shifting of covert attention occurs higher in the brain hierarchy, in the frontal eye field of the frontal cortex (Thompson, Biscoe, \& Sato, 2005). This type of attention may also correspond to the ability to attend to certain thoughts from memory or other mental states that are not immediately linked to sensory information, indicating a more "advanced" use of attention. 2.1.3. Forms of selective attention: object-based attention

Note: This is a near final draft; the final publication is available at Springer via http://dx.doi.org/10.3758/s13423-014-0718-y Please cite: Haladjian, H. H., \& Montemayor, C. (in press). On the evolution of conscious attention. Psychonomic Bulletin \& Review. 
Attention can also be drawn to things in the world that display object-like properties, such as cohesion, symmetry, and common fate (for reviews, see Chen, 2012; Scholl, 2001). Objectbased attention requires a two-stage process that begins with the individuation of objects (a bottom-up process) upon which a selective attention operates such that object features are bound and maintained into a persistent representation, which then can lead to the identification of the object. Together, individuation and identification contribute to the experience of attending to specific items in the world and supports abilities like enumerating sets of items, tracking multiple objects, or attending to a single item in detail.

The first stage of object-based attention, individuation, is a basic data-driven process that selects object-like structures for further processing and is thought to occur in parallel within a cognitively impenetrable module referred to as "early vision". Pylyshyn (1989, 1999, 2001) describes a possible mechanism responsible for individuating visual objects via Visual Indexing Theory. On this view, visual indexes are references or "pointers" to objects in a visual scene that can be maintained over temporal and spatial changes. These primitive data-driven pointers are triggered by objectdefining properties, such as cohesion or rigidity, that parse a discrete object from a visual scene (but without necessarily encoding any of these properties into memory). Once a pointer is assigned, it can attach to and follow a moving object over time. Visual indexes also serve localization and enumeration abilities (Chesney \& Haladjian, 2011; Haladjian \& Pylyshyn, 2011; Trick \& Pylyshyn, 1994), facilitate visual search (Burkell \& Pylyshyn, 1997), and are considered the first step in solving the binding problem (Treisman, 1996; Wolfe, 2012; Wolfe $\&$ Cave, 1999) by providing the core structure for building object-based representations. ${ }^{3}$

The second stage in object-based attention is identification. This stage requires the binding of object features from feature maps, as described in Feature Integration Theory (Treisman \& Gelade, 1980), into sustained mental representations that enables object identification and recognition. Selective attention plays a crucial role in forming persisting object representations by allowing features from a visual scene to build a coherent representation incrementally in visual memory (Treisman, 1998, 2006). In this regard, Object File Theory describes how object-based attention can operate via mid-level "object file" representations (Kahneman, Treisman, \& Gibbs, 1992). Here, a spatiotemporal correspondence is established (to distinguish which object went where) and requires reviewing operations to construct cohesive representations of features and detect changes. Although the binding of features can happen as quickly as 200-ms (Feldman, 2007), the efficiency of this process is sensitive to cognitive load and becomes more difficult when attention or working memory resources are preoccupied with other tasks or multiple object representations (Johnson, Hollingworth, \& Luck, 2008; Wheeler \&

\footnotetext{
${ }^{3}$ The individuation of visual objects is related to demonstrative thoughts and provides a solution to the "reference problem", which is concerned with how an object can be tracked through space and time and be linked to a mental representation (Perry, 1997; Pylyshyn, 2001, 2003, 2007; Siegel, 2002). In this way, attention helps anchor mental representations in the world by providing links to higher-level representations (e.g., object representations in working memory).
}

Note: This is a near final draft; the final publication is available at Springer via http://dx.doi.org/10.3758/s13423-014-0718-y Please cite: Haladjian, H. H., \& Montemayor, C. (in press). On the evolution of conscious attention. Psychonomic Bulletin \& Review. 
Treisman, 2002). Given that these are capacities for basic object perception, similar forms of early visual mechanisms for individuation and identification must be present across species.

The object-based attention model argues that the visual system favors the selection of whole objects in a visual scene as opposed to properties such as location or individual features, and many studies provide substantial support for this object-based attention (e.g., Baylis \& Driver, 1993; Chen, 2012; Kahneman, et al., 1992; O'Craven, Downing, \& Kanwisher, 1999; Scholl, 2001; Scholl, Pylyshyn, \& Feldman, 2001; Yantis, 1992). Object-based representations are formed in visual short-term memory, which is limited in the number of objects and the amount of featural information that can be represented (e.g., Alvarez \& Cavanagh, 2004; Cowan, 2001). Such studies suggest that a more complex form of attention is related to voluntary endogenous attention and requires selectively focused attention to bind and maintain the features of object files. This exemplifies the interaction between low-level and high-level forms of attention that makes the study of attention so complex. Given the more centralized voluntary aspects of this form of attention, its evolution may not necessarily correspond with the evolution of the most basic and adaptive forms of attention (i.e., feature or spatial attention).

In addition to the selection of relevant objects, the inhibition of irrelevant items in the visual scene has been shown to be object-based (Theeuwes, Van der Stigchel, \& Olivers, 2006). In fact, such inhibition is specific to the irrelevant objects marked for inhibition and does not occur in the empty space near those objects (Pylyshyn, 2006; Pylyshyn, Haladjian, King, \&
Reilly, 2008), nor on objects clearly segregated within three-dimensional space (Haladjian, Montemayor, \& Pylyshyn, 2008). Attentional capture is more likely to occur in the empty space between moving objects than on the irrelevant objects that are being inhibited (even when controlling for object-related masking effects). This evidence supports the notion that low-level object individuation has the tendency to operate on both task-relevant and taskirrelevant objects automatically, and that objectbased attention operates in crucial ways that do not always involve the processing of information into conscious awareness (Chou \& Yeh, 2012; Melcher \& Vidnyanszky, 2006; Mitroff, Scholl, \& Wynn, 2005; Norman, Heywood, \& Kentridge, 2013).

Object-based theories provide an account of how detailed representations are formed through the spatiotemporal binding of featural information. In other words, they describe the integration of independently-processed visual features that produce representations that refer to external objects. It is these object representations that are most likely the contents of conscious experience, even though not all object files reach conscious awareness (Mitroff, et al., 2005). Note, however, that this is a claim about content, rather than the basic functions of early visual attention. A major problem with the characterization of the function of consciousness is that these contents may be processed without any associated experience of these contents (i.e., there may be no associated feeling, phenomenal property, or what it is like to be in a representational state with those contents).

Supporting object-based attention are brain areas that are generally considered to be more

Note: This is a near final draft; the final publication is available at Springer via http://dx.doi.org/10.3758/s13423-014-0718-y Please cite: Haladjian, H. H., \& Montemayor, C. (in press). On the evolution of conscious attention. Psychonomic Bulletin \& Review. 
recently evolved. In addition to the inputs from and feedback signals to the visual cortex (Cohen $\&$ Tong, 2013), the superior parietal lobe (above the visual cortex) and right lateral fusiform cortex are involved in object-based attention, including when shifting attention between objects (Yantis \& Serences, 2003). Area MT detects motion and assists in tracking movement (Newsome \& Paré, 1988), and related actions engage inhibitory processes from the extrastriate areas V2 and V4 (Bundesen, Habekost, \& Kyllingsbaek, 2005; Desimone \& Duncan, 1995; Luck, Chelazzi, Hillyard, \& Desimone, 1997; Mangun, 1995; Posner, 1992). These structures have been identified in other higher species, such as pigeons and monkeys, though little research has investigated object-based attention in animals (see Roelfsema, Lamme, \& Spekreijse, 1998; Ushitani, Imura, \& Tomonaga, 2010).

To reiterate, our focus here is on attention as a primitive cognitive function and on why this function is one of the earliest adaptations of the nervous system. We are not, therefore, claiming that the contents to which humans can attend are also part of the early adaptations that constitute the functions of attention in early vision. Contents (presumably conceptual ones) are likely to be related to conscious attention and may not be necessary for basic discrimination tasks, such as feature-based attention. Those who defend the view that attention is identical with consciousness (e.g., Prinz, 2012) must say either that any animal capable of navigating and selecting features from the environment is conscious or that these basic forms of attention do not deserve the name "attention". Because of the evolutionary considerations that serve as theoretical background, as well as the broad consensus that these are empirically confirmed forms of attention, we find both options highly problematic. The early forms of attention are fundamental and adaptive, from which crossmodal attention evolved.

\subsection{Cross-modal attention}

As has been emphasized in the vast literature on visual attention (of which we only presented a small fraction), the recognition of object features within the visual modality requires mappings based on spatiotemporal coordinates. The Feature Integration Theory for visual object recognition is based on this idea (Treisman \& Gelade, 1980). Although there is controversy concerning this proposal (Pylyshyn, 2007), it is uncontroversial that human visual attention is capable of integrating many features that are spatiotemporally organized into a coherent and useful representation. Cross-modal attention in non-human cognition need not be as rich in feature integration as in humans, but it certainly requires mappings between different geometric structures (e.g., sound and vision).

Proprioception and cross-modal attention, therefore, seem to require a centralized nervous system and a centralized way of integrating and interpreting different types of information, which may be the basis of voluntary attention.

Related to this idea, Hommel's Event File Theory proposes an enhanced version of object files that incorporates both features and motor commands (Hommel, 2004, 2005, 2007; Zmigrod, et al., 2009). This theory provides a richer notion of object representations in the sense that these cross-modal sensory representations also integrate action-planning information. In terms of sensory integration, auditory and visual information presented together are often taken to be part of the same

Note: This is a near final draft; the final publication is available at Springer via http://dx.doi.org/10.3758/s13423-014-0718-y Please cite: Haladjian, H. H., \& Montemayor, C. (in press). On the evolution of conscious attention. Psychonomic Bulletin \& Review. 
event (e.g., when you hear and see a motorcycle approaching, and plan to move out of its way). Even with asynchronous presentations of multimodal information (e.g., 350-ms gap between tone and visual stimulus onset), associations can be formed that allow asynchronous features from separate modalities to be considered as part of the same event; this sort of feature binding does not necessarily require an awareness that it is happening, nor does it affect behavior when the temporal asynchrony is consciously perceived (Zmigrod \& Hommel, 2011). The importance of this theory is that it addresses the ultimate purpose of the ability to attend to things in the world and represent them-in order to act on them. This describes a source of agency for the system representing information and is related to complex behaviors such as tool usage.

There is also support for early interactions across modalities in task-irrelevant perceptual learning of cross-modal cueing effects (Batson, Beer, Seitz, \& Watanabe, 2011). That is, when an irrelevant sound is paired with a specific stimulus in a manner that is not obvious to the test subject, subsequent performance can nevertheless be affected after training in a way that indicates a cross-modal association was implicitly learned. In order for these associations to occur, information from different modalities must be integrated in some way, and thus necessitate a mechanism to enable this integration. To this end, cross-modal attention integrates a variety of features, which requires mappings between the different modalities. In addition to object-based or event-based mappings, another mapping concerns egocentric and allocentric frames of reference (Gallistel, 1990a, 1990b) that enable an organism to navigate successfully within an environment. In the case of time, these mappings require a crossmodal window of simultaneity, because each modality has been found to have different simultaneity windows. ${ }^{4}$ The basic idea is that cross-modal information integration and robust integration of memories (episodic and semantic) create a platform for the egocentric perspective that seems to characterize phenomenal consciousness.

Like the previous cases of attention within a single modality, cross-modal attention for features, objects, and regions of space is likely to have been adaptive, as species with brain mechanisms capable of mapping information from one region to another created more robust, complex, and stable representations of their environments. Cross-modal integration is the basis of many processes that increase the probability of succeeding at vital tasks, such as foraging and hunting (Gallistel, 1990a, 1990b). While this seems obvious, it is significant that these mappings require sophisticated representations of the environment, or at least robust forms of memory for space and feature binding not required by more basic forms of attention. This, however, need not entail that these representations or cognitive capacities involve conceptual content.

\subsection{Conceptual content and attention}

The emergence of semantics and conceptual content is a notoriously controversial issue in philosophy and cognitive science. Some philosophers think that only humans have the capacity for conceptualizing and forming beliefs based on concepts (see McDowell, 1994; for

\footnotetext{
${ }^{4}$ See Pöppel (1988) on these findings, and Montemayor (2013) for discussions on the representational characteristics of the cross-modal simultaneity window.
}

Note: This is a near final draft; the final publication is available at Springer via http://dx.doi.org/10.3758/s13423-014-0718-y Please cite: Haladjian, H. H., \& Montemayor, C. (in press). On the evolution of conscious attention. Psychonomic Bulletin \& Review. 
dissent concerning the need for concepts, see Stalnaker, 1984). Conceptual content seems to be deeply associated with the language capacity because of its compositional and generative characteristics (Fodor, 1998). It is also associated with the more complex activities of imagination and metaphor (Lakoff \& Johnson, 1980). All theories of conceptual content relate it to the language capacity or the ability to form beliefs that support inferential reasoning and, therefore, conceptual attention seems to be a recent phenomenon (given the assumption that language and inferential reasoning emerged recently with the evolution of our species).

Without endorsing any specific view on the scope of the conceptual contents of attention (e.g., are they uniquely human or do other species have them?), we would like to illustrate the type of cognitive enrichment that highlyintegrated conceptual contents allow and emphasize their relatively recent evolution. For example, contents are conceptualized in Gestalt phenomena and ambiguous images. In cases like the Necker cube, the image conceptualized as a three-dimensional cube flips back and forth, from appearing to have an upward orientation to a downward one, generating an attention pattern with a specific temporal rate. In other cases, however, the attention pattern is between two very different conceptual contents, as in the duck-rabbit drawing, which can appear to be a rabbit or a duck, depending on how the image is interpreted. This kind of conceptual attention shifting must have appeared at later stages in the evolution of attentional mechanisms. Although they depend on automatic processes (e.g., the back-and-forth switching process characteristic of ambiguous images), these contents of attention are clearly much more conceptualized than the basic forms of selective attention, which constitute more basic features of the visual scene.

Based on similar considerations, enrichments of skill that build on reflex-like capacities must also be based on attention for conceptual contents. Object-based attention provides a possible feature integration mechanism that enables the recognition of external objects, people, and places by comparing these contents to concepts stored in long-term memory. In a very simplistic account, being able to recognize things in the world relies on the binding of features, both basic (such as shape and color) and conceptual (such as seeing a duck or a rabbit). More realistically, however, these basic processes are supplemented by the rich information stored in memory. For example, the detection of only a few features is often sufficient for the brain to predict an object's identity based upon the stored content in long-term memory (see Clark, 2013, for a discussion of related predictive brain processes). Therefore, conceptual cognition relies on basic perceptual processes and has evolved to enable the interaction between these basic processes and stored content in long-term memory in order to increase the efficiency of perception and cognition. This advancement necessitates a complex integration of not only perceptual but also conceptual information (i.e., a process that integrates not only currently attended features but potentially relevant ones in memory).

\subsection{Voluntary attention}

Sustained attention is deeply associated with the passage of time and the sense of self. For this reason, it seems that voluntary (or willfully sustained endogenous attention) must be at the basis of self-awareness. Here an interesting 
issue emerges. There must be two kinds of voluntary attention: with and without selfawareness. Many forms of sustained attention (e.g., keeping track of moving objects, searching for a feature among distractors) can be performed without high forms of selfawareness. But clearly, self-awareness is associated with sustained attention, as when one meditates or recites a phrase to oneself to consolidate memories. A form of sustained attention must have emerged early and is closely related to the described attentional processes (e.g., sustained attention for tracking or focusing on details). The type of voluntary attention that involves a sense of self, however, must be more recent due to the complexity of neural connections required for self-reflection and meta-cognition.

Voluntary attention is contrasted to the more automatic (and primitive) involuntary forms of attentional control. The distinction between involuntary and voluntary attention is often studied as the difference between bottom-up and top-down attention (see Theeuwes, 2010). That is, attention can be stimulus-driven and automatically guided toward external events that involuntarily catch the focus of attention, or it can be voluntarily guided through willful selection. Bottom-up attention includes attentional capture by abrupt onsets of stimuli or sudden changes in motion or luminance (Burnham, 2007; Theeuwes, 1992; Yantis, 1993; Yantis \& Hillstrom, 1994), and can be described by "winner-takes-all" models of attention (e.g., Koch \& Ullman, 1985) that characterize the early processes in feature-based attention. Such forms of involuntary attention can bias the neural activity for selection into higher processes and can affect behavior without reaching conscious awareness.

From an evolutionary perspective, bottomup involuntary attentional processes can be seen as more primitive, earlier adaptations that assist basic evolutionarily-relevant survival abilities, such as procuring food, avoiding prey, or finding mates. These early selection processes are tied to feature and spatial attention, and process information according to the specialized (functional) modules in the brain (Rensink, 2014). As described above, there are forms of attention that are related to more primitive brain regions that operate in a bottom-up and automatic manner. These brain regions emerged early in evolution and include invertebrates, which are animals that usually would not be considered to have consciousness (Griffin \& Speck, 2004).

On the other hand, voluntary and top-down attention can be described as being endogenous and more deliberate, which can bias the competing neural activity in lower-level cognition based on the goals of the current task. Voluntary attention is likely to have evolved later as organisms were required to adapt and respond to more complex representations related to forms of learning, tool usage, and social interactions such as communicating and maintaining social order within groups. These higher-level cognitive processes require a voluntary, sustained form of attention, as well as interactions with other cognitive processes, such as working memory and long-term memory. Animals exhibiting such higher-level behaviors include blue jays, crows, parrots, macaque monkeys, and chimpanzees, as they show signs of tool manipulation or rudimentary language abilities (Griffin \& Speck, 2004). Having a self-

Note: This is a near final draft; the final publication is available at Springer via http://dx.doi.org/10.3758/s13423-014-0718-y Please cite: Haladjian, H. H., \& Montemayor, C. (in press). On the evolution of conscious attention. Psychonomic Bulletin \& Review. 
awareness, however, seems to be a more complex attribute of voluntary attention than mere sustained attention. Self-awareness involves reflecting on the contents of what is being attended and, fundamentally, on one's own conscious perspective because one is not only aware of these contents, but also aware that one is thinking about them.

Whether or not animals possess selfawareness remains debatable, but some have proposed ways in which basic consciousness might be identified in animals (see Edelman, et al., 2005; Griffin \& Speck, 2004; Seth, Baars, \& Edelman, 2005; Seth, Dienes, Cleeremans, Overgaard, \& Pessoa, 2008). For example, Bayne's (2007) theory of "creature consciousness", which specifies whether or not an organism can be said to be phenomenally conscious, requires mechanisms that generate the "phenomenal field" (related to activity in the thalamus), and neural inputs from the different cortical areas responsible for processing sensory and memory-related information. Only after integrative processes occur can consciousness be considered present in animals, but such claims require empirical support. Currently, problem-solving behaviors (e.g., tool usage) in animals provide the best examples of the possible presence of conscious attention in animals (for a review on animal consciousness, see Griffin \& Speck, 2004).

Various brain regions, considered to be more evolutionarily advanced, have been identified to support voluntary top-down attention. These areas include the prefrontal cortex, which is also associated with executive function (Baddeley \& Della Sala, 1996; Petersen \& Posner, 2012). Parietal and frontal regions in the cortex seem to be involved in attentional control by initiating and maintaining attentive states (Yantis \& Serences, 2003). This goal-directed attention, however, remains constrained by low-level computations in the visual system (Yantis, 2000), further showing how top-down and bottom-up processes interact. Similarly, recent studies suggest that feedback and recurrent processes are especially important for explaining how top-down modulation occurs and how conscious attention may arise (Lamme, 2006; Pollen, 2003; Theeuwes, 2010). The anatomy of the brain and its evolution, therefore, strongly suggest that different forms of attention became interfaced and interlocked at different stages in the development of our species, with more advanced forms related to the growing complexity in the cortex and recurrent pathways to the more primitive brain regions. The voluntary/involuntary dichotomy has been challenged recently, however, since there are other forms of attention that do not fall into these categories, such as when learned rewards or habits influence attention (e.g., Awh, Belopolsky, \& Theeuwes, 2012). Nevertheless, most attentional processes tend to fall under one of these two descriptions.

\subsection{Effortless attention}

Effortless attention (like bottom-up attentional processes) is typically considered an involuntary, sensory form of attention that does not always reach conscious awareness. These effortless processes serve to obtain information from the environment for higher-level representations, which often require more effort to maintain. On the other end of this spectrum is effortful attention, which, like top-down attention, is described as focused, deliberate, voluntary, or goal-driven, and produces the subjective feeling of expending effort. 
Some complex attentional processes, however, can be so engrossing that they produce the subjective feeling of being involved in a task effortlessly such that one loses a sense of time (Bruya, 2010). It is this latter version of effortless attention that is particularly insightful, because it may be related to expertise and is suggestive of how memory systems can interact with attention to influence the perception of effort and time. Effortless attention in this sense is a more controversial form of attention (compared to other forms of higher-level attentional processes) and has only recently been discussed in the literature. Similarly, the feeling of "flow" is related to effortless attention, where one's focus is on the mechanics of a physical activity with very little effort or attention to other forms of stimulation (see Csikszentmihalyi, 1997). Flow is typically considered as being closer to a more primary conscious experience, often described as an experience that is "in the moment", which does not include a reflective self-awareness that is more typical of deliberate thoughts.

Assuming that effortless attention is a legitimate form of attention, it seems to have evolved recently and may be associated with the most experientially rich forms of conscious awareness. Necessarily, it would be a form of conscious attention. Moreover, it would also be one of the richest and most informationdemanding forms of attention, suggesting a deep association with complex representation and more sophisticated cognitive tasks, even though these complex representations may not reach conscious awareness themselves. This type of effortless attention involves a level of expertise that requires a willful, effortful attention to be executed many times prior to this experience of effortless attention (e.g., as in procedural learning). This would be related to learning capabilities of the most reflective, deliberate, and advanced type. Effortless attention also presupposes that the agent has self-awareness in order to experience this sense of effortlessness. Because of all these characteristics, it seems that effortless attention, including the experience of flow, must have evolved after many of the brain areas related to more basic kinds of attention developed into their current forms found in humans today. More importantly, effortless attention seems to demand the interrelation between conscious phenomenal awareness (what it is like to experience oneself introspectively) and inputs from all forms of attention.

\section{The evolution of conscious attention}

A brief chronological sketch of the evolution of conscious attention may start with: 1) selective attention for grounding features of the geometry of sensory space, such as spatial and featurebased attention; 2) cross-modal detection of these features that require mappings across different feature maps and interfaces between different geometries; 3) conceptual content; 4) voluntary attention; and 5) forms of effortless attention with very high cognitive demands but little experienced effort. Functional definitions of consciousness, which include integrative mechanisms or global workspace theories, are only associated with 3-5, and most of these accounts locate such capacities only in the very recent evolution of humans. Thus, the dissociation between consciousness and attention follows from strictly evolutionary

Note: This is a near final draft; the final publication is available at Springer via http://dx.doi.org/10.3758/s13423-014-0718-y Please cite: Haladjian, H. H., \& Montemayor, C. (in press). On the evolution of conscious attention. Psychonomic Bulletin \& Review. 
considerations, even if one can define

consciousness functionally (e.g., as the function that integrates information for global broadcast in a linguistic-like format).

The dissociation between consciousness and attention is even more severe if one considers conscious awareness to be a form of illusion (e.g., Humphrey, 2011). Clearly, considering consciousness to be an unsolvable mystery or a primitive feature of the universe that cannot be defined functionally will entail full dissociation from attention. That is, these views preclude any possible overlap between attention (which is defined functionally) and consciousness (which cannot be defined functionally). Therefore, to provide an account of how conscious attention might have evolved, we shall focus on some illusory and spandrel views, rather than on views that entail full dissociation and no possible overlap between consciousness and attention.

If one subscribes to the view that consciousness transcends any functional explanation, then considerations about evolution become irrelevant for the scientific study of consciousness. This conclusion derives from the fact that evolutionary developments are explained traditionally in terms of functions. Some empirically-based views on consciousness, however, also agree that evolutionary explanations are inadequate to account for the nature of consciousness because it cannot be reduced to functions concerning selective or adaptive processes (e.g., Block, 1995). Furthermore, even some who adopt an evolutionary perspective in their explanation of consciousness reject the view that it is an adaptation (e.g., Carruthers, 2000; Dennett, 2005). Those who claim that consciousness has the purpose of providing an illusory basis for social and empathic development (Humphrey, 2011) also fall into this category. Illusion accounts of consciousness, however, could be understood skeptically, as suggesting that consciousness is not the product of evolution because the illusion of a unique subjective perspective may be considered pernicious rather than advantageous.

Nichols and Grantham (2000) argue, however, that the anatomical complexity of systems associated with phenomenal consciousness provides enough evidence that consciousness is in fact an evolutionary adaptation. Their primary claim is that phenomenally conscious experience involves inputs from different modalities as well as different channels within a modality (e.g., different forms of visual features that comprise feature-based attention). These different inputs must be integrated in some manner to produce a unified conscious experience. The integration of these different channels, then, is an indication of a rather complex process and involves many neural structures. Therefore, the structural complexity that engenders phenomenal consciousness should support the idea that consciousness is an adaptation that is present in at least many vertebrates (as some philosophers assume, following Nagel, 1974). Also, dissociations between consciousness and perceptual inputs, such as in blindsight ${ }^{5}$, further

\footnotetext{
${ }^{5}$ Blindsight is a condition where damage to the visual cortex prevents the individual from being able to consciously perceive a visual stimulus, yet they are still able to act upon it (e.g., pick up an object) since the relevant information for the motor system can by-pass the visual cortex (Brogaard, 2012; Kentridge, 2012; Kentridge, Nijboer, \& Heywood, 2008; Weiskrantz, 1996).
}

Note: This is a near final draft; the final publication is available at Springer via http://dx.doi.org/10.3758/s13423-014-0718-y Please cite: Haladjian, H. H., \& Montemayor, C. (in press). On the evolution of conscious attention. Psychonomic Bulletin \& Review. 
support the idea that multiple channels provide input to consciousness, since sometimes these channels can fail to deliver information into conscious awareness even when this input can influence behavior. Various forms of inputs can suffer from such dissociations between the attentional systems for action and those for perception (see Brogaard, 2011; Kentridge, 2012).

The idea that consciousness serves the function of cross-modal and within-modal integration has support from various researchers (for a review, see Baars, 2002). Based on our previous arguments, however, even this view that characterizes consciousness as adaptive would entail dissociation, since a highly integrative, cross-modal conscious attention must have evolved much later than the basic forms of modality-specific selective attention. Consciousness - even as an integrative mechanism - cannot be identical to attention because of these early adaptations of low-level attentional systems and the more recent development of the integrative forms of objectbased and cross-modal attention.

Therefore, most extant accounts of the evolution of consciousness may be reduced to three options: 1) dualist accounts that reject any physical explanations of consciousness; 2) physicalist accounts that reject any evolutionary explanations of the nature of consciousness; and 3) physicalist accounts that propose evolutionary explanations of consciousness, but reject that it is an adaptation (e.g., it is a spandrel). ${ }^{6}$ Consequently, these three options

\footnotetext{
${ }^{6}$ Dualist accounts tend to assume a metaphysical explanation of consciousness, which requires an account outside the physical world; even some interpretations of quantum mechanics seem to suggest some form of
}

entail that conscious attention is not an adaptation because consciousness is not adaptive. In other words, the evidence of integration within and across attention systems that occurs without requiring conscious awareness (e.g., Mudrik, et al., in press) reduces the likelihood that conscious attention is an evolutionary-motivated adaptation. This faces us with the question: what is the purpose of conscious awareness if such integration occurs without it? Furthermore, even views that consider consciousness as adaptive, which are certainly the exception in the contemporary literature (e.g., Nichols \& Grantham, 2000), require a dissociation between basic forms of attention and cross-modal integrative conscious attention.

Since the first two options consider evolution to be theoretically irrelevant in describing consciousness or conscious attention, we shall focus on the third option. There are at least two theories that fall within this third option. The first is that consciousness plays an important cognitive function and can thereby be defined in functionalist computational terms. According to this view, however, consciousness is not an adaptation but rather a spandrel-the result of an accidental combination among adaptive functions, such as language and mindreading. The main role of conscious awareness, then, is to broadcast contents that are computed in a uniform format (presumably conceptual), which plays an essentially epistemic role since it provides access to contents across different modalities for the purpose of providing information to support

dualism (e.g., the von Neumann interpretation). Physicalist accounts require a physical (e.g., neural) basis to phenomenal conscious experience.

Note: This is a near final draft; the final publication is available at Springer via http://dx.doi.org/10.3758/s13423-014-0718-y Please cite: Haladjian, H. H., \& Montemayor, C. (in press). On the evolution of conscious attention. Psychonomic Bulletin \& Review. 
beliefs or goal-driven actions. Dennett (1969, 1991, 2005) and Carruthers (2000) defend this view, as well as most theorists who favor "global broadcast" or "global workspace" views of consciousness (e.g., Baars, 1988; Dehaene \& Naccache, 2001).

The second possibility is that consciousness is a spandrel, but that its function is not epistemically driven - unlike attention, which is epistemically driven because it provides access to contents that justify goal-related beliefs. Thus, according to this view, consciousness is largely integrative but serves an illusory function that creates the appearance of a coherent and unified unique self that enjoys private access to a world inaccessible to anyone else, with important ethical and spiritual consequences - a view defended by Humphrey (2011). Thus the main point of contention between these two spandrel views is whether the main purpose of consciousness is to broadcast information or to produce a useful (though admittedly strange, functionally-speaking) illusion associated with phenomenal content. Nevertheless, both illusion views entail severe forms of dissociation between consciousness and attention.

An important source of confusion regarding the broadcast view is that it seems to suggest that consciousness must be identical to attention, because the purpose of attention - at least cross-modal attention - seems to be to broadcast and give "access" to information (see Prinz, 2012). This claim, however, requires disambiguation because of the different functions and evolutionary development of distinct types of attention. The less dissociative interpretation of this "access" view is that selective attention is an early adaptation while cross-modal attention to conscious contents is a later adaptation. Cross-modal attention, however, may not be sufficient to have global access to uniformly formatted contents, although attention seems to be necessary for this global access.

Even if cross-modal attention guaranteed access to uniformly formatted contents, it would still be a later evolutionary achievement. This would require the development of a global format, the broadcast of information from different specialized areas of the brain, and the presence of all the basic forms of attention. These requirements strongly suggest a dissociation between basic forms of attention and conscious cross-modal attention. Related to this theoretical account of consciousness is the possibility that the presence of reentrant neural processing (i.e., feedback processing, in addition to feedforward, that appears important for complex attentional processes) among brain structures may be an indication of mechanisms that support consciousness (Di Lollo, Enns, \& Rensink, 2000; Hamker, 2005; Lamme, 2003; Seth \& Baars, 2005; Tononi \& Koch, 2008). Complex reentrant networks, especially with the frontal cortex, are also considered later adaptations.

All other interpretations of spandrel views entail a stronger dissociation between consciousness and attention. In particular, illusion views characterize consciousness in terms of the unique and inaccessible perspective of a cohesive self, which demands forms of introspection that are unlikely to be found across species and are certainly beyond the functional aspects of cross-modal attention. In other words, any view on consciousness that requires a subjective or phenomenal story limits

Note: This is a near final draft; the final publication is available at Springer via http://dx.doi.org/10.3758/s13423-014-0718-y Please cite: Haladjian, H. H., \& Montemayor, C. (in press). On the evolution of conscious attention. Psychonomic Bulletin \& Review. 
how much of a relationship it could have with the various forms of attention found in humans and animals. Therefore, all the possible views on the evolution of consciousness and attention show that they must be dissociated to some degree.

Framing the relationship between consciousness and attention in adaptive terms helps solve a problem that exacerbates the difficulties concerning the study of conscious attention: many researchers mean different things when they use the terms "consciousness" and "attention". For example, when researchers use these terms, are they referring to what Block (1995) calls "access" consciousness (the availability of representational content for use by various cognitive systems), or is it experience and the associated idea of "phenomenality" and subjectivity? In other words, is it just attention or attention plus subjective experience (conscious attention)? One crucial advantage of an evolutionary perspective on the relation between consciousness and attention is that $i t$ demonstrates that they must be dissociated regardless of how one defines them among the viable options currently available within the debate. To the best of our knowledge, no other extant view on the relationship between consciousness and attention has this advantage.

Additionally, it becomes clear that conscious attention cannot be either simple selection or pure phenomenality. According to the functional views of consciousness, voluntary and involuntary conscious attention play the role of broadcasting information that can be used for many cognitive purposes - information which is formatted in a common cognitive code. The formatting of conscious contents presents the following problem: whatever conscious attention is, it cannot be simple selection, or even cross-modal attention without quality access to highly integrated contents - a point that is uncontroversial. But then, conscious attention is a lot more than simply phenomenal consciousness because just experiencing contents (e.g., feeling pain or anxiety) need not have the selective and knowledge-seeking (epistemic) functions of attention. One can experience pain and pleasure without having any attention-driven process of selecting information and accessing contents. One also could have reflex reactions to stimuli and produce selective behavior that requires attention, but not experience things such as pain or pleasure. Furthermore, as has been confirmed empirically, many attention processes can happen unconsciously. This indicates that conscious attention is more than phenomenality and requires many sub-processes related to attention.

To summarize our arguments thus far, the earliest forms of attention, including those considered automatic (e.g., feature-based, spatial), act as selection mechanisms to filter relevant information for higher-level processing. These basic forms of attention have been identified across species and appeared very early in the evolution of nervous systems. Through mechanisms such as feature maps and spatial indexing processes, a mid-level objectbased attention developed to facilitate the representation of complex multi-feature objects, allowing for the sustained maintenance of these representations in working memory structures, and for relating them to contents stored in longterm memory. This development may be the crucial step in the production of conscious 
attention, since these systems can perform more complicated tasks beyond simple feature detection, including object tracking, complex visual search tasks, and object recognition. Object-based attention then provides the scaffolding for more complex cognitive processes, including cross-modal integration, maintained activation of representations and attention networks, and various social interactions that include communications and developing a theory of mind. These higher-level processes rely heavily on working memory systems for maintaining and manipulating this information. If a global workspace does indeed occur, it would be somewhere within the interaction between attention and memory, and here is where conscious attention would lie. Clearly, many basic forms of attention must happen before conscious attention occurs.

\section{Conclusion: conscious attention-more than a feeling}

Regardless of what consciousness is, it is certain that conscious attention cannot be a mere feeling or pure "what it is like" (see Nagel, 1974). Attention requires selection, short-term memory, contents, and the kind of cognitive processing that can be defined functionally. Therefore, conscious attention also should have a functional purpose. If conscious attention is indeed an integrative mechanism that combines inputs from different perceptual channels and information stored in long-term memory, then we need to develop a better understanding of how the functions of integration are associated with subjective phenomenal experiences. For example, what it is like to experience pain, and not simply respond to signals from pain receptors without the subjective experience, needs to be associated with the functional aspects of selective and cross-modal attention that are necessary to produce pain experiences (an arguably difficult and controversial issue). The challenge of why conscious attention is not merely phenomenal experience highlights the difficulties ahead in providing a theory of conscious attention. A final theory of conscious attention must incorporate the fact that evolutionary arguments indicate a dissociation between the basic forms of attention and consciousness.

In addition to the studies on blindsight, further support for the dissociation between attentional processes and consciousness comes from studies on motor actions and conscious experience (e.g., Cohen, Cavanagh, Chun, \& Nakayama, 2012; Desmurget et al., 2009; Kühn \& Brass, 2009; Wegner, 2003). Such studies indicate that perceptual decisions and motor commands are executed before one becomes conscious of that decision or intention to make the action, with different neural correlates relating to the subject feeling of action (Filevich et al., 2013). These findings are often used to argue that consciousness is unnecessary for actions, since there are background processes that execute these actions and we just "feel" like we are consciously doing things. Similarly, the separate ventral and dorsal pathways for information processing in the visual cortex indicate that there are independent sources of information for determining what is seen ("vision for perception") and executing motor commands ("vision for action"), and this often results in a dissociation between the information used to plan action and what enters conscious 
awareness. That is, visual information can be processed for the execution of motor commands outside of conscious experience, which argues against the idea that consciousness evolved in order to serve an integrative function to support action. This conclusion suggests, in the very least, that some forms of conscious attention may not be as globally available as some theories assume.

Most of the extant views on consciousness and attention entail a severe dissociation, and even the few views that consider consciousness as adaptive also entail dissociation. This dissociation holds regardless of how "attention" and "consciousness" are defined. Since the current views reject full dissociation, they allow for some form of overlap between the evolutionary distinct processes of consciousness and attention - this conscious attention, however, must outline a strictly functional description of phenomenality. Ultimately, conscious attention must be a spectrum of different processes rather than a single type of process.

One source of data confirming a spectrum of conscious attention concerns learning. Some researchers argue that the case of learning presents a dissociation between consciousness and attention. In particular, some claim that conscious awareness - and not attention - is necessary for learning (e.g., see Lovibond, Liu, Weidemann, \& Mitchell, 2011; Meuwese, et al., 2013). Of course the problem is that reporting mental content requires consciousness and the experiments typically implemented require reportability, either through verbal language or through gestures. Additionally, even when implicit perceptual learning is found under conditions where attention is supposedly not engaged (e.g., the inattentional condition in Meuwese, et al., 2013), whether or not all forms of attention are truly absent in these cases remains debatable, since we would argue that higher-level focused attention may be absent under inattentional conditions, but low-level visual processing, such has feature-based attention, must still be operating. Furthermore, there certainly must be unconscious forms of learning, like procedural or associative learning in humans and animals (Griffin \& Speck, 2004). This suggests that there may be a spectrum of conscious attention processes in learning, some relying more heavily on phenomenal consciousness, while others relying almost exclusively on low-level attention. This relatively new research focus in relation to consciousness may be especially promising in revealing whether or not conscious attention does indeed serve a functional purpose.

As for another promising area of research, recent theories have begun to explore the interaction between working memory and attentional processes in relation to conscious experience. For example, there is evidence for interactions between selective attention and working memory in the presence of top-down modulation, with some shared neural systems (Awh \& Jonides, 2001; Gazzaley \& Nobre, 2011). Another proposed mechanism related to working memory is the "central executive" system (Baddeley \& Della Sala, 1996; Baddeley \& Weiskrantz, 1993), which is thought to help maintain object representations in visual working memory via various attention and working memory processes, such as the visuospatial sketchpad, episodic buffer, and phonological loop (Baddeley, 2000). These memory structures may also support self- 
reflection and help distinguish the source of phenomenal experience, be it from sensory inputs or from long-term memory (Johnson, Hashtroudi, \& Lindsay, 1993; Mitchell \& Johnson, 2009). Together, these components describe ways in which perceptual information is maintained for cognition, which may be necessary for conscious awareness. Indeed, the relationship between working memory and attention is a crucial one that has been recently receiving more attention (for overviews, see Gazzaley \& Nobre, 2011; Hollingworth \& Maxcey-Richard, 2013; Oberauer \& Hein, 2012; Olivers, 2008).

Regardless of whether conscious attention is a single process or a spectrum of processes (as we believe), our main conclusions are the following. First, evolutionary considerations show that attention and consciousness must be dissociated in some form, ranging from functional dissociations (e.g., global versus more localized or within-modality attention) to severe dissociation (as most theories on the evolution of consciousness necessarily assume). Moreover, this conclusion entails that consciousness cannot be identical with attention. That is, although many attentional processes are necessary to provide the contents for conscious experience, attention and consciousness are not identical processes and cannot be reduced to one another given the range of dissociations. Unlike any other extant view, these conclusions hold regardless of how one defines the terms "consciousness" and "attention". It remains possible that the overlap between consciousness and attention, or conscious attention, serves a functional purpose, but this has yet to be clearly defined or adequately supported by empirical evidence. The task now is to examine this relationship given the fact that the most common forms of attention evolved independently and prior to any form of phenomenal consciousness.

\section{Acknowledgments}

This paper is based on an upcoming book by the authors (Montemayor \& Haladjian, in press).

Part of this research was funded by a postdoctoral fellowship in the Foundational Processes of Behavior at the University of Western Sydney (HHH).

\section{References}

Alvarez, G. A., \& Cavanagh, P. (2004). The capacity of visual short-term memory is set both by visual information load and by number of objects. Psychological Science, 15(2), 106-111. doi: 10.1111/j.0963-7214.2004.01502006.x

Alvarez, G. A., \& Oliva, A. (2008). The representation of simple ensemble visual features outside the focus of attention. Psychological Science, 19(4), 392-398. doi: 10.1111/j.1467-9280.2008.02098.x

Awh, E., Belopolsky, A. V., \& Theeuwes, J. (2012). Top-down versus bottom-up attentional control: A failed theoretical dichotomy. Trends in Cognitive Sciences, 16(8), 437-443. doi: $10.1016 / \mathrm{j} . \mathrm{tics} .2012 .06 .010$

Awh, E., \& Jonides, J. (2001). Overlapping mechanisms of attention and spatial working memory. Trends in Cognitive Sciences, 5(3), 119-126. doi: 10.1016/S1364-6613(00)01593-X

Baars, B. J. (1988). A Cognitive Theory of Consciousness. Cambridge: Cambridge University Press.

Note: This is a near final draft; the final publication is available at Springer via http://dx.doi.org/10.3758/s13423-014-0718-y Please cite: Haladjian, H. H., \& Montemayor, C. (in press). On the evolution of conscious attention. Psychonomic Bulletin \& Review. 
Baars, B. J. (1998). The functions of consciousness:

Reply. Trends in Neurosciences, 21(5), 201. doi: 10.1016/S0166-2236(98)01252-1

Baars, B. J. (2002). The conscious access hypothesis: Origins and recent evidence. Trends in Cognitive Sciences, 6(1), 47-52. doi: 10.1016/S1364-6613(00)01819-2

Baddeley, A. D. (2000). The episodic buffer: A new component of working memory? Trends in Cognitive Sciences, 4(11), 417-423. doi: 10.1016/S1364-6613(00)01538-2

Baddeley, A. D., \& Della Sala, S. (1996). Working memory and executive control. Philosophical Transactions of the Royal Society of London B: Biological Sciences, 351(1346), 1397-1493. doi: 10.1098/rstb.1996.0123

Baddeley, A. D., \& Weiskrantz, L. (Eds.). (1993). Attention: Selection, Awareness, and Control: A Tribute to Donald Broadbent. Oxford: Clarendon Press.

Batson, M. A., Beer, A. L., Seitz, A. R., \& Watanabe, T. (2011). Spatial shifts of audiovisual interactions by perceptual learning are specific to the trained orientation and eye. Seeing and Perceiving, 24(6), 579-594. doi: 10.1163/187847611X603738

Baylis, G. C., \& Driver, J. (1993). Visual attention and objects: Evidence for hierarchical coding of location. Journal of Experimental Psychology: Human Perception and Performance, 19(3), 451-470. doi: 10.1037/0096-1523.19.3.451

Bayne, T. (2007). Conscious states and conscious creatures: Explanation in the scientific study of consciousness. Philosophical Perspectives, 21(1), 1-22. doi: 10.1111/j.15208583.2007.00118.x

Beauchamp, M. S., Petit, L., Ellmore, T. M., Ingeholm, J., \& Haxby, J. V. (2001). A parametric fMRI study of overt and covert shifts of visuospatial attention. Neuroimage, 14(2), 310-321. doi: 10.1006/nimg.2001.0788

Block, N. (1995). On a confusion about a function of consciousness. Behavioral and Brain Sciences,
18(2), 227-247. doi:

$10.1017 / \mathrm{S} 0140525 \mathrm{X} 00038188$

Brefczynski, J. A., \& DeYoe, E. A. (1999). A

physiological correlate of the 'spotlight' of visual attention. Nature Neuroscience, 2(4), 370-374. doi: $10.1038 / 7280$

Brogaard, B. (2011). Are there unconscious perceptual processes? Consciousness and Cognition, 20(2), 449-463. doi: 10.1016/j.concog.2010.10.002

Brogaard, B. (2012). Non-visual consciousness and visual images in blindsight. Consciousness and Cognition, 21(1), 595-596. doi: 10.1016/j.concog.2011.12.003

Bruya, B. (2010). Effortless Attention: A New Perspective in the Cognitive Science of Attention and Action. Cambridge, MA: MIT Press.

Bundesen, C., Habekost, T., \& Kyllingsbaek, S. (2005). A neural theory of visual attention: Bridging cognition and neurophysiology. Psychological Review, 112(2), 291-328. doi: 10.1037/0033-295X.112.2.291

Burkell, J. A., \& Pylyshyn, Z. W. (1997). Searching through subsets: A test of the visual indexing hypothesis. Spatial Vision, 11(2), 225-258. doi: 10.1163/156856897X00203

Burnham, B. R. (2007). Displaywide visual features associated with a search display's appearance can mediate attentional capture. Psychonomic Bulletin \& Review, 14(3), 392-422. doi: 10.3758/BF03194082

Carrasco, M. (2011). Visual attention: The past 25 years. Vision Research, 51(13), 1484-1525. doi: 10.1016/j.visres.2011.04.012

Carruthers, P. (2000). Phenomenal Consciousness. Cambridge: Cambridge University Press.

Chalmers, D. J. (1996). The Conscious Mind: In Search of a Fundamental Theory. New York: Oxford University Press.

Chen, Z. (2012). Object-based attention: A tutorial review. Attention, Perception, \& Psychophysics, 74(5), 784-802. doi: 10.3758/s13414-012-0322$\mathrm{Z}$

Note: This is a near final draft; the final publication is available at Springer via http://dx.doi.org/10.3758/s13423-014-0718-y Please cite: Haladjian, H. H., \& Montemayor, C. (in press). On the evolution of conscious attention. Psychonomic Bulletin \& Review. 
Chesney, D. L., \& Haladjian, H. H. (2011). Evidence for a shared mechanism used in multiple-object tracking and subitizing. Attention, Perception, \& Psychophysics, 73(8), 2457-2480. doi: 10.3758/s13414-011-0204-9

Chou, W .-L., \& Yeh, S.-L. (2012). Object-based attention occurs regardless of object awareness. Psychonomic Bulletin \& Review, 19(2), 225231. doi: 10.3758/s13423-011-0207-5

Clark, A. (2013). Whatever next? Predictive brains, situated agents, and the future of cognitive science. Behavioral and Brain Sciences, 36(3), 181-204. doi: 10.1017/S0140525X12000477

Cohen, E. H., \& Tong, F. (2013). Neural Mechanisms of Object-Based Attention. Cerebral Cortex doi: 10.1093/cercor/bht303

Cohen, M. A., Cavanagh, P., Chun, M. M., \& Nakayama, K. (2012). The attentional requirements of consciousness. Trends in Cognitive Sciences, 16(8), 411-417. doi: 10.1016/j.tics.2012.06.013

Cosmides, L., \& Tooby, J. (2013). Evolutionary psychology: New perspectives on cognition and motivation. Annual Review of Psychology, 64, 201-229. doi:

10.1146/annurev.psych.121208.131628

Cowan, N. (2001). The magical number 4 in shortterm memory: A reconsideration of mental storage capacity. Behavioral and Brain Sciences, 24(1), 87-114; discussion 114-185. doi: 10.1017/S0140525X01373922

Csikszentmihalyi, M. (1997). Finding Flow: The Psychology of Engagement with Everyday Life (1st ed.). New York: Basic Books. de Fockert, J. W., Rees, G., Frith, C. D., \& Lavie, N. (2004). Neural correlates of attentional capture in visual search. Journal of Cognitive Neuroscience, 16(5), 751-759. doi: $10.1162 / 089892904970762$

Dehaene, S., \& Naccache, L. (2001). Towards a cognitive neuroscience of consciousness: Basic evidence and a workspace framework.
Cognition, 79(1-2), 1-37. doi: 10.1016/S00100277(00)00123-2

Dennett, D. C. (1969). Content and Consciousness. London: Routledge.

Dennett, D. C. (1991). Consciousness Explained (1st ed.). Boston, MA: Little, Brown and Co.

Dennett, D. C. (2005). Sweet Dreams: Philosophical Obstacles to a Science of Consciousness. Cambridge, MA: MIT Press.

Desimone, R., \& Duncan, J. (1995). Neural mechanisms of selective visual attention. Annual Review of Neuroscience, 18, 193-222. doi: 10.1146/annurev.ne.18.030195.001205

Desmurget, M., Reilly, K. T., Richard, N., Szathmari, A., Mottolese, C., \& Sirigu, A. (2009). Movement intention after parietal cortex stimulation in humans. Science, 324(5928), 811813. doi: 10.1126/science.1169896

Di Lollo, V., Enns, J. T., \& Rensink, R. A. (2000). Competition for consciousness among visual events: The psychophysics of reentrant visual processes. Journal of Experimental Psychology: General, 129(4), 481-507. doi: 10.1037/00963445.129.4.481

Edelman, D. B., Baars, B. J., \& Seth, A. K. (2005). Identifying hallmarks of consciousness in nonmammalian species. Consciousness and Cognition, 14(1), 169-187. doi: 10.1016/j.concog.2004.09.001

Eriksen, C. W., \& Yeh, Y.-Y. (1985). Allocation of attention in the visual field. Journal of Experimental Psychology: Human Perception and Performance, 11(5), 583-597. doi: 10.1037/0096-1523.11.5.583

Feinberg, T. E., \& Mallatt, J. (2013). The evolutionary and genetic origins of consciousness in the Cambrian Period over 500 million years ago. Frontiers in Psychology, 4. doi: 10.3389/fpsyg.2013.00667

Feldman, J. (2007). Formation of visual "objects" in the early computation of spatial relations. Perception \& Psychophysics, 69(5), 816-827. doi: 10.3758/BF03193781

Note: This is a near final draft; the final publication is available at Springer via http://dx.doi.org/10.3758/s13423-014-0718-y Please cite: Haladjian, H. H., \& Montemayor, C. (in press). On the evolution of conscious attention. Psychonomic Bulletin \& Review. 
Filevich, E., Vanneste, P., Brass, M., Fias, W., Haggard, P., \& Kühn, S. (2013). Brain correlates of subjective freedom of choice. Consciousness and Cognition, 22(4), 1271-1284. doi: 10.1016/j.concog.2013.08.011

Finlay, B. L., \& Brodsky, P. B. (2006). Cortical evolution as the expression of a program for disproportionate growth and the proliferation of areas. In J. H. Kaas (Ed.), Evolution of Nervous Systems: A Comprehensive Reference (1st ed., Vol. 1, pp. 73-96). Amsterdam: Elsevier Academic Press.

Fitch, W. T., Hauser, M. D., \& Chomsky, N. (2005). The evolution of the language faculty: Clarifications and implications. Cognition, 97(2), 179-210; discussion 211-125. doi: 10.1016/j.cognition.2005.02.005

Fodor, J. A. (1983). The Modularity of Mind: An Essay on Faculty Psychology. Cambridge, MA: MIT Press.

Fodor, J. A. (1998). Concepts: Where Cognitive Science Went Wrong. Oxford: Oxford University Press.

Gallistel, C. R. (1990a). The Organization of Learning. Cambridge, MA: MIT Press.

Gallistel, C. R. (1990b). Representations in animal cognition: An introduction. Cognition, 37(1-2), 1-22. doi: 10.1016/0010-0277(90)90016-D

Gazzaley, A., \& Nobre, A. C. (2011). Top-down modulation: Bridging selective attention and working memory. Trends in Cognitive Sciences, 16(2), 129-135. doi: 10.1016/j.tics.2011.11.014

Gegenfurtner, K. R. (2003). Cortical mechanisms of colour vision. Nature Reviews Neuroscience, 4(7), 563-572. doi: 10.1038/nrn1138

Geisler, W. S., Perry, J. S., Super, B. J., \& Gallogly, D. P. (2001). Edge co-occurrence in natural images predicts contour grouping performance. Vision Research, 41(6), 711-724. doi: 10.1016/S0042-6989(00)00277-7

Gould, S. J., \& Lewontin, R. C. (1979). The spandrels of San Marco and the Panglossian paradigm: A critique of the adaptationist programme. Proceedings of the Royal Society of London. Series B: Biological Sciences, 205(1161), 581-598. doi: 10.2307/77447

Griffin, D. R., \& Speck, G. B. (2004). New evidence of animal consciousness. Animal Cognition, 7(1), 5-18. doi: 10.1007/s10071-003-0203-x

Haladjian, H. H., Montemayor, C., \& Pylyshyn, Z. W. (2008). Segregating targets and nontargets in depth eliminates inhibition of nontargets in Multiple Object Tracking. Visual Cognition, 16(1), 107-110. doi: 10.1007/s10071-003-0203$\mathrm{x}$

Haladjian, H. H., \& Pylyshyn, Z. W. (2011). Enumerating by pointing to locations: A new method for measuring the numerosity of visual object representations. Attention, Perception, \& Psychophysics, 73(2), 303-308. doi: 10.3758/s13414-010-0030-5

Hamker, F. H. (2005). The reentry hypothesis: The putative interaction of the frontal eye field, ventrolateral prefrontal cortex, and areas V4, IT for attention and eye movement. Cerebral Cortex, 15(4), 431-447. doi: 10.1093/cercor/bhh146

Hollingworth, A., \& Maxcey-Richard, A. M. (2013). Selective maintenance in visual working memory does not require sustained visual attention. Journal of Experimental Psychology: Human Perception and Performance, 39(4), 1047-1058. doi: 10.1037/a0030238

Hommel, B. (2004). Event files: Feature binding in and across perception and action. Trends in Cognitive Sciences, 8(11), 494-500. doi: 10.1016/j.tics.2004.08.007

Hommel, B. (2005). How much attention does an event file need? Journal of Experimental Psychology: Human Perception and Performance, 31(5), 1067-1082. doi: 10.1037/0096-1523.31.5.1067

Hommel, B. (2007). Feature integration across perception and action: Event files affect response choice. Psychological Research, 71(1), 42-63. doi: 10.1007/s00426-005-0035-1

Note: This is a near final draft; the final publication is available at Springer via http://dx.doi.org/10.3758/s13423-014-0718-y Please cite: Haladjian, H. H., \& Montemayor, C. (in press). On the evolution of conscious attention. Psychonomic Bulletin \& Review. 
Horowitz, T. S., Holcombe, A. O., Wolfe, J. M., Arsenio, H. C., \& DiMase, J. S. (2004). Attentional pursuit is faster than attentional saccade. Journal of Vision, 4(7), 585-603. doi: 10.1167/4.7.6

Hubel, D. H. (1995). Eye, Brain, and Vision. New York: Scientific American Library.

Hubel, D. H., \& Wiesel, T. N. (1962). Receptive fields, binocular interaction and functional architecture in the cat's visual cortex. The Journal of Physiology, 160, 106-154.

Humphrey, N. (2011). Soul Dust: The Magic of Consciousness. Princeton: Princeton University Press.

Johnson, J. S., Hollingworth, A., \& Luck, S. J. (2008). The role of attention in the maintenance of feature bindings in visual short-term memory. Journal of Experimental Psychology: Human Perception and Performance, 34(1), 41-55. doi: 10.1037/0096-1523.34.1.41

Johnson, M. K., Hashtroudi, S., \& Lindsay, D. S. (1993). Source monitoring. Psychological Bulletin, 114(1), 3-28. doi: 10.1037/00332909.114.1.3

Kahneman, D., Treisman, A., \& Gibbs, B. J. (1992). The reviewing of object files: Object-specific integration of information. Cognitive Psychology, 24(2), 175-219. doi: 10.1016/00100285(92)90007-O

Kastner, S., \& Ungerleider, L. G. (2000).

Mechanisms of visual attention in the human cortex. Annual Review of Neuroscience, 23, 315341. doi: 10.1146/annurev.neuro.23.1.315

Kentridge, R. W. (2012). Blindsight: Spontaneous scanning of complex scenes. Current Biology, 22(15), R605-606. doi: 10.1016/j.cub.2012.06.011

Kentridge, R. W., Nijboer, T. C. W., \& Heywood, C. A. (2008). Attended but unseen: Visual attention is not sufficient for visual awareness. Neuropsychologia, 46(3), 864-869. doi: 10.1016/j.neuropsychologia.2007.11.036
Koch, C. (2004). The Quest for Consciousness: A Neurobiological Approach. Denver, CO: Roberts \& Company Publishers.

Koch, C., \& Ullman, S. (1985). Shifts in selective visual attention: Towards the underlying neural circuitry. Human Neurobiology, 4(4), 219-227. doi: 10.1007/978-94-009-3833-5_5

Kovács, I. (1996). Gestalten of today: Early processing of visual contours and surfaces. Behavioural Brain Research, 82(1), 1-11. doi: 10.1016/S0166-4328(97)81103-5

Kühn, S., \& Brass, M. (2009). Retrospective construction of the judgement of free choice. Consciousness and Cognition, 18(1), 12-21. doi: 10.1016/j.concog.2008.09.007

Lakoff, G., \& Johnson, M. (1980). Metaphors We Live By. Chicago: University of Chicago Press.

Lamme, V. A. F. (2003). Why visual attention and awareness are different. Trends in Cognitive Sciences, 7(1), 12-18. doi: 10.1016/S13646613(02)00013-X

Lamme, V. A. F. (2006). Towards a true neural stance on consciousness. Trends in Cognitive Sciences, 10(11), 494-501. doi: 10.1016/j.tics.2006.09.001

Lovibond, P. F., Liu, J. C. J., Weidemann, G., \& Mitchell, C. J. (2011). Awareness is necessary for differential trace and delay eyeblink conditioning in humans. Biological Psychology, 87(3), 393-400. doi:

10.1016/j.biopsycho.2011.05.002

Luck, S. J., Chelazzi, L., Hillyard, S. A., \& Desimone, R. (1997). Neural mechanisms of spatial selective attention in areas V1, V2, and V4 of macaque visual cortex. Journal of Neurophysiology, 77(1), 24-42.

Mangun, G. R. (1995). Neural mechanisms of visual selective attention. Psychophysiology, 32(1), 418. doi: 10.1146/annurev.ne.18.030195.001205

Marr, D. (1980). Visual information processing: The structure and creation of visual representations. Philosophical Transactions of the Royal Society

Note: This is a near final draft; the final publication is available at Springer via http://dx.doi.org/10.3758/s13423-014-0718-y Please cite: Haladjian, H. H., \& Montemayor, C. (in press). On the evolution of conscious attention. Psychonomic Bulletin \& Review. 
of London B: Biological Sciences, 290(1038), 199-218. doi: 10.1098/rstb.1980.0091

Maunsell, J. H., \& Treue, S. (2006). Feature-based attention in visual cortex. Trends in Neurosciences, 29(6), 317-322. doi: 10.1016/j.tins.2006.04.001

McDowell, J. H. (1994). Mind and World. Cambridge, MA: Harvard University Press.

Melcher, D., \& Vidnyanszky, Z. (2006). Subthreshold features of visual objects: Unseen but not unbound. Vision Research, 46(12), 18631867. doi: 10.1016/j.visres.2005.11.021

Merker, B. (2005). The liabilities of mobility: A selection pressure for the transition to consciousness in animal evolution. Consciousness and Cognition, 14(1), 89-114. doi: 10.1016/S1053-8100(03)00002-3

Meuwese, J. D. I., Post, R. A. G., Scholte, H. S., \& Lamme, V. A. F. (2013). Does perceptual learning require consciousness or attention? Journal of Cognitive Neuroscience, 25(10), 1579-1596.doi: 10.1162/jocn_a_00424

Milner, A. D., \& Goodale, M. A. (1995). The Visual Brain in Action (1st ed.). Oxford: Oxford University Press.

Milner, A. D., \& Goodale, M. A. (2008). Two visual systems re-viewed. Neuropsychologia, 46(3), 774-785. doi: 10.1016/j.neuropsychologia.2007.10.005

Mitchell, K. J., \& Johnson, M. K. (2009). Source monitoring 15 years later: What have we learned from fMRI about the neural mechanisms of source memory? Psychological Bulletin, 135(4), 638-677. doi: 10.1037/a0015849

Mitroff, S. R., Scholl, B. J., \& Wynn, K. (2005). The relationship between object files and conscious perception. Cognition, 96(1), 67-92. doi: $10.1167 / 3.9 .338$

Montemayor, C. (2013). Minding Time: A Philosophical and Theoretical Approach to the Psychology of Time. Boston: Brill.
Montemayor, C., \& Haladjian, H. H. (in press). Consciousness, Attention, and Conscious Attention. Cambridge, MA: MIT Press.

Mudrik, L., Faivre, N., \& Koch, C. (in press). Information integration without awareness. Trends in Cognitive Sciences(0). doi: 10.1016/j.tics.2014.04.009

Nagel, T. (1974). What is it like to be a bat? Philosophical Review, 83(4), 435-450.

Newsome, W. T., \& Paré, E. B. (1988). A selective impairment of motion perception following lesions of the middle temporal visual area (MT). The Journal of Neuroscience, 8(6), 2201-2211.

Nichols, S., \& Grantham, T. (2000). Adaptive complexity and phenomenal consciousness. Philosophy of Science, 67(4), 648-670.

Norman, L. J., Heywood, C. A., \& Kentridge, R. W. (2013). Object-based attention without awareness. Psychological Science, 24(6), 836843. doi: 10.1177/0956797612461449

O'Craven, K. M., Downing, P. E., \& Kanwisher, N. (1999). fMRI evidence for objects as the units of attentional selection. Nature, 401(6753), 584587. doi: $10.1038 / 44134$

Oberauer, K., \& Hein, L. (2012). Attention to information in working memory. Current Directions in Psychological Science, 21(3), 164169. doi: $10.1177 / 0963721412444727$

Olivers, C. N. L. (2008). Interactions between visual working memory and visual attention. Frontiers in Bioscience, 13, 1182-1191. doi: 10.2741/2754

Perry, J. (1997). Indexicals and demonstratives. In R. Hale \& C. Wright (Eds.), Companion to the Philosophy of Language. Oxford: Blackwell.

Petersen, S. E., \& Posner, M. I. (2012). The attention system of the human brain: 20 years after. Annual Review of Neuroscience, 35, 73-89. doi: 10.1146/annurev-neuro-062111-150525

Peterson, M. S., Kramer, A. F., \& Irwin, D. E. (2004). Covert shifts of attention precede involuntary eye movements. Perception \& Psychophysics, 66(3), 398-405. doi: 10.3758/BF03194888

Note: This is a near final draft; the final publication is available at Springer via http://dx.doi.org/10.3758/s13423-014-0718-y Please cite: Haladjian, H. H., \& Montemayor, C. (in press). On the evolution of conscious attention. Psychonomic Bulletin \& Review. 
Polger, T., \& Flanagan, O. (2002). Consciousness, adaptation and epiphenomenalism. In J. H. Fetzer (Ed.), Consciousness Evolving (pp. 2141). Amsterdam: John Benjamins Pub.

Pollen, D. A. (2003). Explicit neural representations, recursive neural networks and conscious visual perception. Cerebral Cortex, 13(8), 807-814. doi: 10.1093/cercor/13.8.807

Pöppel, E. (1988). Mindworks: Time and Conscious Experience (1st ed.). Boston: Harcourt Brace Jovanovich .

Posner, M. I. (1980). Orienting of attention. Quarterly Journal of Experimental Psychology, 32(1), 3-25.

Posner, M. I. (1992). Attention as a cognitive and neural system. Current Directions in Psychological Science, 1(1), 11-14. doi: 10.1111/1467-8721.ep10767759

Posner, M. I., Cohen, Y., \& Rafal, R. D. (1982). Neural systems control of spatial orienting. Philosophical Transactions of the Royal Society of London B: Biological Sciences, 298(1089), 187-198. doi: 10.1098/rstb.1982.0081

Posner, M. I., Snyder, C. R., \& Davidson, B. J. (1980). Attention and the detection of signals. Journal of Experimental Psychology, 109(2), 160-174. doi: 10.1037/0096-3445.109.2.160

Prinz, J. J. (2012). The Conscious Brain: How Attention Engenders Experience. New York: Oxford University Press.

Pylyshyn, Z. W. (1989). The role of location indexes in spatial perception: A sketch of the FINST spatial-index model. Cognition, 32(1), 65-97. doi: 10.1016/0010-0277(89)90014-0

Pylyshyn, Z. W. (1999). Is vision continuous with cognition? The case for cognitive impenetrability of visual perception. Behavioral and Brain Sciences, 22(3), 341-365; discussion 366-423.

Pylyshyn, Z. W. (2001). Visual indexes, preconceptual objects, and situated vision. Cognition, 80(1-2), 127-158. doi: 10.1016/S0010-0277(00)00156-6
Pylyshyn, Z. W. (2003). Seeing and Visualizing: It's Not What You Think. Cambridge, MA: MIT Press.

Pylyshyn, Z. W. (2006). Some puzzling findings in multiple object tracking (MOT): II. Inhibition of moving nontargets. Visual Cognition, 14(2), 175-198. doi: 10.1080/13506280544000200

Pylyshyn, Z. W. (2007). Things and Places: How the Mind Connects with the World. Cambridge, MA: MIT Press.

Pylyshyn, Z. W., Haladjian, H. H., King, C. E., \& Reilly, J. E. (2008). Selective nontarget inhibition in Multiple Object Tracking. Visual Cognition, 16(8), 1011-1021. doi: 10.1080/13506280802247486

Rensink, R. A. (2014). A function-centered taxonomy of visual attention. In P. Coates \& S. Coleman (Eds.), Phenomenal Qualities: Sense, Perception, and Consciousness. Oxford: Oxford University Press.

Roelfsema, P. R., Lamme, V. A. F., \& Spekreijse, H. (1998). Object-based attention in the primary visual cortex of the macaque monkey. Nature, 395(6700), 376-381. doi: 10.1038/26475

Rosenthal, D. M. (2008). Consciousness and its function. Neuropsychologia, 46(3), 829-840. doi: 10.1016/j.neuropsychologia.2007.11.012

Scholl, B. J. (2001). Objects and attention: The state of the art. Cognition, 80(1-2), 1-46. doi: 10.1016/S0010-0277(00)00152-9

Scholl, B. J., Pylyshyn, Z. W., \& Feldman, J. (2001). What is a visual object? Evidence from target merging in multiple object tracking. Cognition, 80(1-2), 159-177. doi: 10.1016/S00100277(00)00157-8

Seth, A. K., \& Baars, B. J. (2005). Neural Darwinism and consciousness. Consciousness and Cognition, 14(1), 140-168. doi: 10.1016/j.concog.2004.08.008

Seth, A. K., Baars, B. J., \& Edelman, D. B. (2005). Criteria for consciousness in humans and other mammals. Consciousness and Cognition, 14(1), 119-139. doi: 10.1016/j.concog.2004.08.006

Note: This is a near final draft; the final publication is available at Springer via http://dx.doi.org/10.3758/s13423-014-0718-y Please cite: Haladjian, H. H., \& Montemayor, C. (in press). On the evolution of conscious attention. Psychonomic Bulletin \& Review. 
Seth, A. K., Dienes, Z., Cleeremans, A., Overgaard, M., \& Pessoa, L. (2008). Measuring consciousness: Relating behavioural and neurophysiological approaches. Trends in Cognitive Sciences, 12(8), 314-321. doi: 10.1016/j.tics.2008.04.008

Siegel, S. (2002). The role of perception in demonstrative reference. Philosophers' Imprint, 2(1), 1-21.

Smith, J. M., \& Szathmáry, E. (1995). The Major Transitions in Evolution. New York: W.H. Freeman Spektrum.

Spelke, E. (1994). Initial knowledge: Six suggestions. Cognition, 50(1-3), 431-445. doi: 10.1016/0010-0277(94)90039-6

Spencer, H. (1855). The Principles of Psychology (3rd edition, 1987 ed.). New York: D. Appleton \& Company .

Stalnaker, R. (1984). Inquiry. Cambridge, MA: MIT Press.

Striedter, G. F. (2006). Precis of principles of brain evolution. Behavioral and Brain Sciences, 29, 1 36. doi: 10.1017/S0140525X06009010

Tallon-Baudry, C. (2012). On the neural mechanisms subserving consciousness and attention. Frontiers in Psychology, 2, 397. doi: 10.3389/fpsyg.2011.00397

Talsma, D., Senkowski, D., Soto-Faraco, S., \& Woldorff, M. G. (2010). The multifaceted interplay between attention and multisensory integration. Trends in Cognitive Sciences, 14(9), 400-410. doi: 10.1016/j.tics.2010.06.008

Tanskanen, T., Saarinen, J., Parkkonen, L., \& Hari, R. (2008). From local to global: Cortical dynamics of contour integration. Journal of Vision, 8(7), 15 11-12. doi: 10.1167/8.7.15

Theeuwes, J. (1992). Perceptual selectivity for color and form. Perception \& Psychophysics, 51(6), 599-606. doi: 10.3758/BF03211656

Theeuwes, J. (2010). Top-down and bottom-up control of visual selection. Acta Psychologica, 135(2), 77-99. doi: 10.1016/j.actpsy.2010.02.006
Theeuwes, J., Van der Stigchel, S., \& Olivers, C. N. L. (2006). Spatial working memory and inhibition of return. Psychonomic Bulletin \& Review, 13(4), 608-613. doi: 10.3758/BF03193970

Thompson, K. G., Biscoe, K. L., \& Sato, T. R. (2005). Neuronal basis of covert spatial attention in the frontal eye field. The Journal of Neuroscience, 25(41), 9479-9487. doi: 10.1523/JNEUROSCI.0741-05.2005

Tomasello, M. (1999). The Cultural Origins of Human Cognition. Cambridge, MA: Harvard University Press.

Tononi, G. (2008). Consciousness as integrated information: A provisional manifesto. The Biological Bulletin, 215(3), 216-242.

Tononi, G. (2012). Integrated information theory of consciousness: An updated account. Archives Italiennes de Biologie, 150(2-3), 56-90. doi: 10.4449/aib.v149i5.1388

Tononi, G., \& Koch, C. (2008). The neural correlates of consciousness: An update. Annals of the New York Academy of Sciences, 1124, 239-261. doi: 10.1196/annals.1440.004

Tooby, J., \& Cosmides, L. (1995). Mapping the evolved functional organization of the mind and brain. In M. S. Gazzaniga \& E. Bizzi (Eds.), The Cognitive Neurosciences (pp. 1185-1197). Cambridge, MA: MIT Press.

Tootell, R. B., Reppas, J. B., Kwong, K. K., Malach, R., Born, R. T., Brady, T. J., Rosen, B. R., \& Belliveau, J. W. (1995). Functional analysis of human MT and related visual cortical areas using magnetic resonance imaging. The Journal of Neuroscience, 15(4), 3215-3230.

Treisman, A. (1996). The binding problem. Current Opinion in Neurobiology, 6(2), 171-178. doi: 10.1016/S0959-4388(96)80070-5

Treisman, A. (1998). Feature binding, attention, and object perception. Philosophical Transactions of the Royal Society of London B: Biological Sciences, 353(1373), 1295-1306. doi: $10.1098 /$ rstb.1998.0284

Note: This is a near final draft; the final publication is available at Springer via http://dx.doi.org/10.3758/s13423-014-0718-y Please cite: Haladjian, H. H., \& Montemayor, C. (in press). On the evolution of conscious attention. Psychonomic Bulletin \& Review. 
Treisman, A. (2006). How the deployment of attention determines what we see. Visual Cognition, 14(4-8), 411-443. doi: $10.1080 / 13506280500195250$

Treisman, A., \& Gelade, G. (1980). A featureintegration theory of attention. Cognitive Psychology, 12(1), 97-136. doi: 10.1016/00100285(80)90005-5

Treisman, A., \& Zhang, W. (2006). Location and binding in visual working memory. Memory and Cognition, 34(8), 1704-1719. doi: 10.3758/BF03195932

Trick, L. M., \& Pylyshyn, Z. W. (1994). Why are small and large numbers enumerated differently? A limited-capacity preattentive stage in vision. Psychological Review, 101(1), 80-102. doi: 10.1037/0033-295X.101.1.80

Ungerleider, L. G., \& Haxby, J. V. (1994). 'What' and 'where' in the human brain. Current Opinion in Neurobiology, 4(2), 157-165. doi: 10.1016/0959-4388(94)90066-3

Ushitani, T., Imura, T., \& Tomonaga, M. (2010). Object-based attention in chimpanzees (Pan troglodytes). Vision Research, 50(6), 577-584. doi: 10.1016/j.visres.2010.01.003

van Boxtel, J. J. A., Tsuchiya, N., \& Koch, C. (2010). Consciousness and attention: On sufficiency and necessity. Frontiers in Psychology, 1(217). doi: 10.3389/fpsyg. 2010.00217

Ward, R. (2013). Attention, evolutionary perspectives. In H. E. Pashler (Ed.), Encyclopedia of the Mind (Vol. 1, pp. 53-56). Thousand Oaks, CA: Sage Publications.

Wegner, D. M. (2003). The mind's best trick: How we experience conscious will. Trends in Cognitive Sciences, 7(2), 65-69. doi: 10.1016/S1364-6613(03)00002-0

Weiskrantz, L. (1996). Blindsight revisited. Current Opinion in Neurobiology, 6(2), 215-220. doi: 10.1016/S0959-4388(96)80075-4

Wheeler, M. E., \& Treisman, A. M. (2002). Binding in short-term visual memory. Journal of
Experimental Psychology: General, 131(1), 4864. doi: 10.1037/0096-3445.131.1.48

Wiederman, S. D., \& O'Carroll, D. C. (2013). Selective attention in an insect visual neuron. Current Biology, 23(2), 156-161. doi: 10.1016/j.cub.2012.11.048

Wolfe, J. M. (2012). The binding problem lives on: Comment on Di Lollo. Trends in Cognitive Sciences, 16(6), 307-308. doi: 10.1016/j.tics.2012.04.013

Wolfe, J. M., \& Cave, K. R. (1999). The psychophysical evidence for a binding problem in human vision. Neuron, 24(1), 11-17. doi: 10.1016/S0896-6273(00)80818-1

Wright, R. D., \& Ward, L. M. (2008). Orienting of Attention. Oxford: Oxford University Press.

Yantis, S. (1992). Multielement visual tracking: Attention and perceptual organization. Cognitive Psychology, 24(3), 295-340. doi: 10.1016/00100285(92)90010-Y

Yantis, S. (1993). Stimulus-driven attentional capture and attentional control settings. Journal of Experimental Psychology: Human Perception and Performance, 19(3), 676-681. doi: 10.1037/0096-1523.19.3.676

Yantis, S. (2000). Goal-directed and stimulus-driven determinants of attentional control. In S.

Monsell \& J. Driver (Eds.), Control of Cognitive Processes. Attention and Performance XVIII (pp. 73-103). Cambridge, MA: MIT Press.

Yantis, S., \& Hillstrom, A. P. (1994). Stimulusdriven attentional capture: Evidence from equiluminant visual objects. Journal of Experimental Psychology: Human Perception and Performance, 20(1), 95-107. doi: 10.1037/0096-1523.20.1.95

Yantis, S., Schwarzbach, J., Serences, J. T., Carlson, R. L., Steinmetz, M. A., Pekar, J. J., \& Courtney, S. M. (2002). Transient neural activity in human parietal cortex during spatial attention shifts. Nature Neuroscience, 5(10), 995-1002. doi: $10.1038 / \mathrm{nn} 921$

Note: This is a near final draft; the final publication is available at Springer via http://dx.doi.org/10.3758/s13423-014-0718-y Please cite: Haladjian, H. H., \& Montemayor, C. (in press). On the evolution of conscious attention. Psychonomic Bulletin \& Review. 
Yantis, S., \& Serences, J. T. (2003). Cortical mechanisms of space-based and object-based attentional control. Current Opinion in Neurobiology, 13(2), 187-193. doi: 10.1016/S0959-4388(03)00033-3

Yeshurun, Y., \& Carrasco, M. (1998). Attention improves or impairs visual performance by enhancing spatial resolution. Nature, 396(6706), 72-75. doi: $10.1038 / 23936$

Zmigrod, S., \& Hommel, B. (2011). The relationship between feature binding and consciousness:
Evidence from asynchronous multi-modal stimuli. Consciousness and Cognition, 20(3), 586-593. doi: 10.1016/j.concog.2011.01.011 Zmigrod, S., Spapé, M., \& Hommel, B. (2009). Intermodal event files: Integrating features across vision, audition, taction, and action. Psychological Research, 73(5), 674-684. doi: 10.1007/s00426-008-0163-5

Note: This is a near final draft; the final publication is available at Springer via http://dx.doi.org/10.3758/s13423-014-0718-y Please cite: Haladjian, H. H., \& Montemayor, C. (in press). On the evolution of conscious attention. Psychonomic Bulletin \& Review . 